\title{
Effects of Moderate Thermal Environments on Cognitive Performance: A Multidisciplinary Review
}

\author{
Fan Zhang ${ }^{1}$, Richard de Dear ${ }^{2}$, Peter Hancock ${ }^{3}$ \\ ${ }^{1}$ Griffith School of Engineering and the Built Environment, Griffith University, QLD 4222, Australia \\ ${ }^{2}$ School of Architecture, Design and Planning, The University of Sydney, NSW 2006, Australia \\ ${ }^{3}$ Department of Psychology, Institute for Simulation and Training, University of Central Florida, Orlando, FL 32826, \\ $U S A$
}

${ }^{*}$ Corresponding Author:

Richard de Dear, School of Architecture, Design and Planning, The University of Sydney, NSW 2006, Australia. T: +61 293515603 E: richard.dedear@sydney.edu.au

\begin{abstract}
The effect of the thermal environment on performance and productivity has been a focus of interest among indoor environmental researchers for nearly a century, but most of that work has been conducted in relative isolation from the cognate disciplines of human performance evaluation. The present review examines thermal environmental effects on cognitive performance research conducted across multiple disciplines. After differentiating performance from productivity, we compare the two dominant conceptual models linking thermal stress to performance; (1) the inverted-U concept and (2) the extended-U relationship. The inverted-U specifies a single optimum temperature (or its corresponding subjective thermal sensation) at which performance is maximised. In contrast, the extended-U model posits a broad central plateau across which there is no discernible thermal effect on cognitive performance. This performance plateau is bounded by regions of progressive performance decrements in more extreme thermal conditions. The contradictions between these opposing conceptual models might derive from various confounding factors at play in their underlying research bases. These include, inter alia, environment-related, task-related, and performer-related factors, as well as their associated two-way and three-way interaction effects. Methodological discrepancies that might also contribute to the divergence of these conceptual models are evaluated, along with the proposed causal mechanisms underlying the two models. The weight of research evidence reviewed in this paper suggests that the extended-U hypothesis fits the relationship between moderate thermal environments and cognitive performance. In contrast to the inverted- $U$ relationship, implemention of the extended- $U$ in indoor climate control implies substantial reductions in building energy demand, since it permits the heating and cooling setpoint deadband to expand across the full width of the thermal comfort zone, or even slightly further during emergencies such as peak demand events on the electricity grid. Use of personal comfort systems can further extend the thermostat setpoint range beyond the comfort zone.
\end{abstract}

Keywords: thermal environment; thermal stress; cognitive performance; the inverted-U model; the extended-U model

List of Abbreviations: HVAC, heating, ventilation and air conditioning; REHVA, Federation of European Heating, Ventilation and Air Conditioning Associations; ASHRAE, American Society of Heating, Refrigerating, and AirConditioning Engineers; GPA, grade point average; TSV, Thermal Sensation Vote; IEQ, Indoor Environmental Quality;; PMV, Predicted Mean Vote; WBGT, wet-bulb globe temperature; ET, effective temperature; LTM, Long-Term Memory; WM, Working Memory; EDT, Environmental Determinism Theory; PCS, Personal Comfort Systems; CLT, cognitive load theory; SWAT, Subjective Workload Assessment Technique; EEG, electroencephalogram; fMRI, functional Magnetic Resonance Imaging; fNIRS, functional Near-Infrared Spectroscopy; ECG, electrocardiography 


\section{Introduction}

\subsection{Thermal Environments and Human Performance}

The notion of climatic influences over human affairs has a very long history, probably dating back to the Hippocratic writings on "Airs, Waters and Places" circa 400 BC ([1], p.4), but its fullest expression had to wait until the so-called climatic determinists of the early Twentieth Century. The most controversial determinist, Ellsworth Huntington, assembled specious post hoc evidence in support of his ethnocentric contention that $3{ }^{\circ} \mathrm{C}$ outdoors was optimal for mental work under the conditions of housing that prevailed in Connecticut at that time [2]. Simple correlational field studies found that factory outputs in tinplate, steel, and glass industries were generally lower during summers $[3,4,5]$. In munitions factories, it was observed that accident rates increased as temperature varied from $20{ }^{\circ} \mathrm{C}$ [6]. In the coal industry, work rates tapered off as temperatures rose from $17{ }^{\circ} \mathrm{C}$ to $32{ }^{\circ} \mathrm{C}$ at $80 \%$ relative humidity [7]. These early studies were especially concerned with physical tasks, their completion rates, associated error rates and safety in traditional industrial settings. However, in recent decades more rigorous investigation into the effect of the thermal environment on human cognitive performance has gathered momentum across diverse disciplines. These range from environmental psychology, to physiology, ergonomics, to air conditioning engineering, as well as neuroscience, sports science, education and even linguistics. This field is bifurcated into studies with conditions approaching intolerable thermal stress and those of only moderate thermal load, in or near optimum comfort. Thermal stress is of most relevance in military and industrial settings where the concern is with safety and survival under extreme conditions [8]. Moderate thermal environmental research is predominantly focused on civilians in or near the comfort zone $[9,10]$.

Heat stress is a common risk factor across diverse activities in mining, shearing, farming, manufacturing, firefighting and other emergency activities, outdoor sports, as well as military occupations. The settings for cold stress also include military operations but also include fishing trawler work, emergency disaster work, and winter sports [11]. Severe environmental heat can compromise the cardiovascular system's ability to maintain a constant body temperature due to an accumulation of body heat, resulting in physiological dysfunction, heat exhaustion and, if left unchecked, ultimately death $[12,13]$. Similarly, severe cold exposure prompts a variety of compensatory physiological responses, but if they are unable to maintain body heat content, a decrement in core temperature ensues, resulting in mental confusion, unconsciousness, and finally death due to heart failure [14,15]. While the physiological responses to environmental heat or cold are well understood, their impact on cognition remains relatively less clear $[13,16]$, particularly for cold exposures $[9,17,18,19]$.

The focus of the present paper is on indoor thermal environments where, depending on outdoor climate, building structure, internal heating/cooling loads, and the active heating and cooling equipment in place, temperatures vary from the high-teens to the low-thirties $\left({ }^{\circ} \mathrm{C}\right)$. These moderate indoor thermal environments are far from the hyper- and hypothermic scenarios described above because they pose no threat to health and safety. Nevertheless they are still capable of exerting adverse impacts on building occupants' cognitive performance, although the literature remains conflicted on the significance of these impacts.

\subsection{Thermal Environments and Building Energy Use}

The range of indoor temperatures deemed acceptable has a strong bearing on building energy requirements because it constrains the geographic scope as well as the seasonal duration when passive designs [20] are able to achieve acceptable indoor environments. Secondly, the indoor design temperature range directly impacts energy required by heating, ventilation and air conditioning (HVAC) systems to achieve them [21]. Up until about the end of the last century the range of indoor design temperatures was mostly couched in terms of thermal comfort. Simple comfort models suggested that a range of $\pm 1.5^{\circ} \mathrm{C}$ around an invariant optimum temperature could ensure $90 \%$ occupant thermal acceptability $[22,23]$. However, more recent adaptive thermal comfort models have challenged these narrow temperature prescriptions with strong empirical evidence that indoor comfort temperatures are dependent on outdoor climatic conditions (e.g. $[24,25])$. The adaptive comfort approach encourages warmer indoor temperatures in warmer climate zones and seasons, and vice versa in cooler climates and seasons.

In response to this debunking of the comfort arguments HVAC peak bodies such as The Federation of European Heating, Ventilation and Air Conditioning Associations (REHVA) and The American Society of Heating, Refrigerating, and Air- 
conditioning Engineers (ASHRAE) shifted their justifications for tight indoor temperature control away from occupant comfort towards occupant productivity. The REHVA Guidebook [26] and ASHRAE Handbook of Fundamentals [27] depict a very narrow indoor temperature range for optimal productivity, which has resulted in significant summer overcooling and winter over-heating worldwide $[28,29,30]$. Ideally, HVAC systems should provide satisfactory thermal conditions and indoor air quality at the minimal expense of energy consumption and negative impact on the environment [31]. In reality buildings accounted for one third of total global final energy use in 2010 [32], much of it related to indoor environmental quality, particularly thermal energy uses [28,29,33,34]. Currently, the building sector is the largest energy consumer worldwide [35] and a typical office building HVAC system accounts for approximately $40 \%$ of total-building energy and $70 \%$ of base-building energy [36]. In Australia the summer indoor thermal performance specifications of 22.5 $\pm 1.5^{\circ} \mathrm{C}$ embedded in most commercial office tenancy agreements [37] are below the ASHRAE standard- 55 summer comfort zone [38]. Such energy intensive over-cooling in commercial buildings is ubiquitous in many developed countries. Despite being widely derided as "the luxurious discomfort of the rich" [30] requiring excessive energy use [39], it is simplistically justified in terms of productivity gains from expensive human resources. Since REHVA and ASHRAE exert a strong influence on air conditioning practices, HVAC-related energy use, and greenhouse gas emissions well beyond their European and North American jurisdictions, it behoves us to critically review the scientific evidence put forward in support of temperature effects on cognitive performance and productivity.

This paper presents a multidisciplinary review of the studies focusing on the effects of moderate thermal environment on cognitive performance. It describes the systematic review methodology in Section 2; three similar concepts (activity, performance and productivity) are differentiated in Section 3; Section 4 introduces two overarching conceptual models linking thermal stress and cognitive performance - the inverted-U model and the extended-U model; Section 5 then reconciles conflicts between these two models by identifying mediating factors, discovering underlying mechanisms behind the two models, and exploring methodological discrepancies leading to divergence of models. Section 6 discusses the practical implications of the two models in terms of indoor environmental control and attendant building energy; Section 7 presents the final conclusions of the review and Section 8 identifies fruitful future research topics.

\section{Methodology}

\subsection{Multidisciplinary approach}

The research theme of thermal environment vs. human performance gained rapid popularity probably after the emergence of indoor environmental quality (IEQ) concept [40] and accompanying research questions on IEQ effects on office productivity $[41,42,43,44,45,46]$. Being one of the most significant IEQ factors in terms of energy costs, indoor thermal environment has received close attention in the research literature. Due to the applied nature of the IEQ field, focus has been on establishing links between physical indoor environmental factors and human responses as an approach to optimizing building management, operation and control [47]. Arithmetic relationships have been proposed by different researchers to quantify the productivity decrement in percentage terms as room temperature (or thermal sensation) deviates from the temperature optimum. These functions have then often been subjected to cost-benefit analyses that trade off the costs of lost productivity from the building's workforce against the costs of variations in building and building services design, retrofits, and operational facilities' management practices $[46,48,49,50,51,52,53]$. However, carried out through specific IEQ disciplinary lens, these studies often lack underlying theories and ignore causal mechanisms. In his wide-ranging survey of the indoor environmental research domain Corsi ([54], p.231) observed that "... indoor air scientists all too often work in narrow trenches, interacting primarily with those they have interacted with for years, content to dig more deeply into that of which they already have significant knowledge, and unaware of the connections that their work may have to those who dig in other trenches." This intellectual insularity is clearly evident in cognitive performance research theme in the indoor environmental sciences and engineering (e.g. Seppänen and Fisk [50], Seppänen et al. [52], Kosonen \& Tan [55], Jensen et al. [56], Lan and Lian [57], Lan et al. [58], Lan et al. [53]) which have generally drawn conclusions diverging from those in the cognate disciplines of human performance evaluation (e.g. Fox [17], Grether [59], Ramsey and Morrissey [60], McIntyre [61], Hancock [62], Kobrick and Fine [63], Parsons [64], Ramsey [19], Pilcher et al. [65], Hancock et al. [10], Gaoua [16], Taylor et al. [66], Schmit et al. [67] and López-Sánchez and Hancock [68]). 
In order to thoroughly understand thermal effects on cognitive performance, we have systematically reviewed the multidisciplinary literature in this topic as broadly and comprehensively as possible. Two distinct theoretical perspectives have emerged. The first posits a dose-response relationship between the indoor thermal environment and cognitive performance, with any deviation from thermal optimum leading to a decrement in performance. The second position asserts that, depending on the thermal intensity of exposure, type of cognitive activity, and other attenuating factors, externally imposed cognitive demands can be absorbed by the buffering capacity or "cognitive reserve" of the subject, with little or no deleterious effect appearing until those adaptive resources are depleted. This synthesis converges on these two prevailing conceptual models - the inverted-U model and the extended-U model. Predicated upon this multidisciplinary foundation, the aims of this review are:

1) To clarify the relationship between performance and productivity and discuss measures of testing thermal environmental impacts on both of them.

2) To summarize the influential intervening factors in relation to thermal effects on cognitive performance with a view to explaining the divergence of these two competing conceptual models; the inverted-U and the extendedU.

3) To identify potential methodological discrepancies that might account for inconsistent conclusions arising from the competing conceptual models.

4) To discuss the practical implications of two conceptual models for the design, engineering and operation of built environments.

\subsection{Method of systematic literature search}

Peer-reviewed journal articles, conference papers, books and doctoral theses across a wide range of disciplines have been searched with Google Scholar, Science Direct, Scopus, Elsevier, and ProQuest. The keywords driving the searches included: cognitive performance, human performance, task performance, performance response, productivity, cognitive load, cognitive function, mental workload; thermal environment, thermal stress, thermal comfort, temperature, heat, and cold. After reviewing the initial group of papers, we looked at the reference lists of downloaded papers for more specifically relevant papers. The final pool of research papers was drawn from eight major disciplines - psychology, health and medicine, energy and building, neuroscience and neurology, human factors and ergonomics, physiology, geriatrics and gerontology, as well as business, economics and management. Table 1 lists 73 key journals from these disciplines for the literature reviewed in this study.

Table 1 Disciplines and journals of the reviewed studies

\section{Clarification of Key Concepts}

The focus of this paper is on the impacts of moderate indoor thermal environments on human performance, specifically cognitive performance. Before proceeding it is essential to differentiate three related but distinct concepts: (1) human activity, (2) performance and (3) productivity. Activity encompasses general pursuits and can involve both psychological and physiological components, but is not directed towards any specific operational goal [64]. In contrast, Performance is the outcome of a goal-directed activity where the performers deliberately regulate their behaviour in order to achieve that goal [64]. There is no commonly agreed definition for Productivity. Sink [69] and Oseland [70] claim that productivity can be expressed in terms of efficiency, i.e. a ratio of input to output. Here we use Parsons' definition - the extent to which activities generate useful performance in terms of achieving the systemic goals of an organization [64]. According to this definition, productivity of a school student may be represented by their grade point average (GPA), while in a customer service centre, productivity may be expressed as the number of customers served within a specific period of time and how satisfied those customers are with the quality of service they received. The critical point is that productivity can involve many dimensions other than performance per se, e.g. social factors such as business and social culture, relationship with colleagues; organizational factors such as organizational structure, job security, workload, management; and personal factors such as injury, loss of sleep, life events, health/well-being, and financial stress, to mention just a few $[71,72,73]$. 
An adverse thermal environment may interfere with an activity by affecting the underlying processes involved in the activity. For example, a cold classroom might undermine finger dexterity, thereby negatively affecting students' typing or data-entry activities. However, this may or may not affect performance, depending on how important the affected activity is to the completion of the task [64]. Thus, it may still be possible to maintain stable performance in a computerbased language test if the students' finger dexterity is affected by a cold classroom, but writing skills may not be significantly jeopardized. The role of classroom thermal environments in students' overall productivity, or GPA, could potentially be important, but it is far from obvious given the myriad factors at play, such as the learning culture of the school, the quality of teaching, students' socio-economic backgrounds, not to mention their level of motivation. The effects of thermal environment on human activity, performance and productivity have been illustrated in Figure 1.

Figure 1 The effects of thermal environment on human activity, performance and productivity, adapted from [64] and [73]

It is not easy to measure the effect of thermal environment on human performance, especially complex, realistic job/task in actual workplaces, because there are many variables related to specific tasks in specific contexts that cannot be adequately accounted for. Consequently in performance science, a reductionist approach [64] is often adopted by dividing the job/task into components, and testing the thermal impacts on respective components and factors. Then an approximate prediction can be made about the effects of thermal environment on the overall job/task performance $[64,74]$. Testing the effect of thermal environment on workers' productivity, especially in office context, will be more problematic. Mawson ([75], p.1) states that "... productivity is comparatively easy to understand and measure in a manufacturing economy, but as our economies have migrated from manufacturing to service and on to knowledge-based, so the whole issue of assessing productivity has become less clear". The lack of clarity and agreement in the definition and constituents of productivity also contributes to controversy in selection of appropriate approaches to office productivity measurement $[47,70,76,77,78]$. Commonly adopted productivity measures include performance tasks, selfperceived productivity, and absenteeism [47,48,70,73,76,77,79,80,81]. However, the validity of these metrics has been questioned. For example, the simulated performance tasks may not realistically reflect the actual job contents in actual workplaces [73,81]; self-perceived productivity cannot reflect the actual productivity $[47,73,79]$; absenteeism may not be sensitive to the environment $[47,73,79]$.

In the indoor environment field, the terms performance and productivity are often used interchangeably, and performance measures are also commonly adopted as a proxy for workplace productivity, as evidenced by large number of studies focusing on quantifying "productivity loss" due to adverse thermal environments [52,53,55,56,57,58,71,82,83,84,85]. The effects of thermal environment on productivity cannot be readily quantified, particularly with simulated performance tests. For one reason, simulated performance tasks do not accurately represent the nature of real work carried out in actual workplaces. Furthermore, the effects of other factors of productivity beyond environmental factors cannot be eliminated from the research design (see Section 5.3.4). Several researchers have expressed similar opinions but none have stated it more bluntly than Parsons, an ergonomist who generalised that no general conclusion could be made regarding the effects of thermal environments on productivity [64]. He has pointed out that "Determining influences of climate on individual performance may be a rather subtle way of investigating productivity. More important effects may be behavioural in terms of sickness or accidents, absenteeism from the workplace or from work altogether, and how easy it is to distract the person from the main task" ([64], p.404-405). Similarly, Smither [86], Cairns [87], Onyeizu [73], Byrd and Onyeizu [81] have all asserted that social and organizational effects swamp environmental factors.

\section{Conceptual Models Linking Environmental Stress and Performance}

In environmental psychology environmental stress is defined as a negative subjective psychological response to an environmental stimulus [88]. Environmental stress occurs when the demands of the ambient environment overwhelm an individual's capacity to deal with those demands. There are four types of environmental stressors identified by Evans and Cohen [89]: cataclysmic events, stressful life events, daily travails and ambient stressors. Indoor environmental temperature falls into the ambient stressor category for building occupants. Despite numerous studies from diverse 
disciplines and research groups around the world, consensus on the effects of thermal environmental stress on human performance remains elusive. Various theories and psychological models have been proposed to link ambient stressors with cognitive performance, but the following section is confined to reviewing the two leading contenders.

\subsection{The Inverted-U Model}

Arousal theory $[90,91,92]$ has been the most influential and ubiquitous model perhaps in all of the stress literature (e.g. [9,10,93,94]). It postulates an inverted-U relationship and is alternatively known as the Yerkes-Dodson law [95]. Performance of a particular task improves as arousal increases until reaching an optimal level for the task in question. Beyond this optimum, performance starts to decline when the arousal level continues to rise, and likewise with reductions below the optimal level of arousal. In regards to the effects of thermal environment on cognitive performance, the same inverted-U relationship has been assumed, substituting arousal level with the intensity of the environmental thermal load (e.g. $[96,97,98,99])$. In summary, as the environmental temperature or its subjective perception (e.g. Thermal Sensation Vote - TSV) increases, the arousal level of the performer also increases, which in turn causes cognitive performance to improve. However, after passing through the single, critical, or optimal point of ambient temperature (or optimum TSV), cognitive performance starts decreasing with increasing heat load.

In the indoor environmental science domain, arousal theory, with its associated inverted-U relationship, has held sway for several decades, judging by the number of citations it has received. Seppänen and Fisk [50] along with Seppänen et al. [52] have emerged as the most influential studies in this body of literature. In these meta-analyses they collated 24 previously published laboratory and field studies, then fitted an inverted-U relationship to the summary data. Their fitted model shows performance increasing as temperatures increased towards $21.6^{\circ} \mathrm{C}$, then decreasing in temperatures beyond $22^{\circ} \mathrm{C}$ (Figure 2). The same inverted-U relationship is mirrored in the ASHRAE Handbook of Fundamentals [27] and REHVA Guidebook No. 6 [26], which are widely regarded as the definitive guideline for HVAC engineers the world over. Instead of predicting performance from room temperature, as in Seppänen et al. [52], the graph in the $A S H R A E$ Handbook shows the $\mathrm{x}$-axis as room temperature relative to the optimal comfort temperature $\mathrm{T}_{\mathrm{c}}$ or neutrality for the group. Despite the very wide scattering of actual data points in the meta-analysis (Figure 3), ASHRAE's Handbook of Fundamentals graph shows a smooth parabolic curve for performance, peaking at the optimum comfort temperature (corresponding to "neutral" thermal sensation), and then tapering off as soon as room temperature deviates from neutrality (Figure 3).

Figure 2 Relative performance vs. temperature adapted from Seppänen et al. [52]

Figure 3 Relative performance of office work vs. deviation from optimal comfort temperature $\mathrm{T}_{\mathrm{C}}$ adapted from ASHRAE Handbook of Fundamentals [27]

Several other indoor environmental scientists have correlated cognitive performance metrics with Thermal Sensation Vote (TSV) instead of indoor temperature, obtaining broadly consistent results to (ASHRAE) Handbook of Fundamentals, as shown in Figure 4. A notable exception is Jiang et al. [100] in which pupils' attention, perception, memory and comprehension, and logical reasoning performance were examined, and finding that response efficiency peaked at TSV of -1.4 (between thermal sensations of "cool" and "slightly cool"), which was much lower than the values observed for adults. Regarding adult studies, the model of Jensen et al. [56] indicated optimum performance of an arithmetic addition task occurring when the TSV was -1 (slightly cool), which was lower than that established by Lan et al. [53] who found the optimum performance corresponded with a close-to-neutral TSV $=-0.25$ for arithmetical calculation, typing, logical reasoning and memory tasks. This was also echoed by the Geng et al. [83] model's optimum performance on tests of concentration, arithmetic calculation and memory, occurring close to TSV=0, and in further support, Cui et al. [101] found the maximum memory typing performance occurred at $\mathrm{TSV}=+0.14$.

Recognising that room temperature is only one of the causal factors affecting the human heat-balance, researchers such as Kosonen and Tan [55] has replaced the independent variable in their research designs with integrated indices of 
thermal environment such as the Predicted Mean Vote (PMV) ${ }^{1}$, which is expressed on the same 7-point Likert scale as TSV (Figure 4). Kosonen and Tan [55] re-analysed research data of Wyon et al. [102], and Wyon [48,103] and reported that optimum level of office productivity assessed by thinking and typing tasks occurred when the PMV value was -0.21 , corresponding to an operative temperature of $20^{\circ} \mathrm{C}$ for participants wearing relatively heavy indoor clothing (estimated to be 1.16 clo).

Figure 4 The inverted-U relationship of cognitive performance proposed in various studies using thermal sensation vote as the independent variable instead of temperature (data from Kosonen \& Tan [55]; Jensen et al. [56]; Lan et al. [53]; Cui et al. [101]; Geng et al. [83]; Jiang et al. [100])

\subsection{The Extended-U Model}

The extended-U model, initially proposed by Hancock and Warm [104], is also referred to as the Maximal Adaptability Model. In contrast to the inverted-U model, the central tenet of the extended-U model is that human performance remains relatively stable across a broad range of acceptable temperatures, but it rapidly deteriorates at the boundaries of thermal acceptability (Figure 5). Thermal stress exerts its adverse impacts on performance by consuming and ultimately depleting the performers' attentional resources (see [105]). The normative zone falls in the middle of the continuum of input stress intensity, and it is here that zero compensatory effort is required of the participant in order for them to maintain optimal performance. The comfort zone encompasses broader conditions than the normative zone, but cognitive adjustments are easily accomplished within the comfort zone in order to maintain a near-optimum level of performance. However, when the environmental stress exceeds the comfort zone, attentional resources begin to be depleted. At first, equivalent or even improved performance can still be achieved by psychological adaptive behaviours such as attentional focus [106]. Because of the central role played by psychological adaptability this region is referred to as the psychological zone of maximal adaptability in Figure 5. When the stress level continues to increase, human performance deteriorates as attentional resources begin to be depleted. This is represented in Figure 5 by the dashed line at the boundary of the psychological zone of maximal adaptability. Further increase in stress intensity pushes the performer beyond their physiological zone of maximal adaptability toward incipient life-threatening circumstances.

Figure 5 The extended-U model linking stress and human performance $[93,104]$

The extended-U model has garnered broad acceptance and currency across a range of disciplines with the notable exception of HVAC engineering and the cognate indoor environmental sciences. It has been confirmed by several authoritative literature reviews on this topic (e.g. $[10,16,19,65,66,67])$, none of which were published in the HVAC engineering and building science outlets. For example, Ramsey [19] summarized a large collection of relevant performance studies and concluded that mental or simple tasks would most likely undergo negligible performance loss in hot environments, and may even be enhanced, at least for brief exposures. Pilcher et al. [65] categorized 22 studies into five wet-bulb globe temperature (WBGT ${ }^{2}$ ) ranges, and found that the greatest performance decrement occurred in both the coldest $\left(<10{ }^{\circ} \mathrm{C}\right.$ WBGT or $11.5^{\circ} \mathrm{C}$ air temperature at $\left.50 \% \mathrm{RH}\right)$ and hottest conditions $\left(\geq 32.2^{\circ} \mathrm{C}\right.$ WBGT or $34.8^{\circ} \mathrm{C}$ air temperature at $50 \% \mathrm{RH}$ ), while the broad central range spanning from 21.1 to $26.6{ }^{\circ} \mathrm{C}$ WBGT $\left(23\right.$ to $29{ }^{\circ} \mathrm{C}$ at $50 \%$ $\mathrm{RH}$ ) had no discernible effect on performance, confirming predictions from the extended-U model. In Hancock et al.'s [10] meta-analysis of 49 separate studies providing 528 effect sizes, the original studies were classified into four effective

\footnotetext{
1 Predicted Mean Vote (PMV) is a comfort index that combines the effects of four environmental parameters (air temperature, mean radiant temperature, humidity and air speed) plus two personal parameters (metabolic heat production and clothing insulation level) [27]. PMV is expressed on the same 7-point thermal sensation scale as TSV.

2 Wet-bulb globe temperature (WBGT) index: an environmental heat stress index that combines dry-bulb temperature $t_{d b}$, a naturally ventilated (not aspirated) wet-bulb temperature $t_{\mathrm{wb}}$, and black globe temperature $t_{\mathrm{g}}$, is widely used for estimating the heat stress potential of industrial environments [27]. WBGT is commonly approximated as $0.7 \times \mathrm{t}_{\mathrm{wb}}+0.3 \times \mathrm{t}_{\mathrm{db}}[65]$.
} 
temperature (old ET ${ }^{3}$ ) ranges: below $25.7^{\circ} \mathrm{C}, 25.7^{\circ} \mathrm{C}-29.4{ }^{\circ} \mathrm{C}, 29.4^{\circ} \mathrm{C}-35.2^{\circ} \mathrm{C}$, and $35.2{ }^{\circ} \mathrm{C}$ and above. Hancock et al. found that, "... with the exception of the lowest temperature range, it is clear that the effect size 4 variation sequentially increases across the three remaining categories. This gives rise to the proposition that performance is relatively stable over much of the temperature range but exhibits radical variation at the highest extreme " ([10], p.862) and this pattern represents a core feature of the extended-U theory of stress and performance. There's also evidence accumulating from the indoor environment domain that is consistent with the extended-U model (e.g. Tanabe \& Nishihara [107]; Witterseh et al. [108]; Fang et al. [109]; Haneda et al. [110]; Lan \& Lian [111]; Lan et al. [57]; Lan et al. [58]; Melikov et al. [112]; Cui et al. [113]; Maula et al. [114]; Zhang \& de Dear [115]; Zhang et al. [116]; Schiavon et al. [117]; Liu et al. [118], although the original authors may not have interpreted their findings within the extended-U framework at the time of their publications.

\section{Conflicts between the Different Models}

Previous literature reviews and formal meta-analyses have identified a number of potential explanations of the apparent contradictions between different studies of moderate thermal environmental effects on cognitive performance (e.g. $[9,10,16,19,66,119,120])$. Besides potential confounders there are also methodological differences that have also contributed to apparently contradictory conclusions.

\subsection{Confounding Factors Mediating Thermal Effects on Cognitive Performance}

Numerous variables that one might suspect of having an influence on mental performance were necessarily overlooked when comparing results from such a diversity of research designs. These potential confounders can be classified as environment-related, task-related, and performer-related factors.

\subsubsection{Environment-related Factors}

\section{- Intensity of Thermal Stress}

More extreme temperature exposures can be expected to result in larger performance decrements than moderate temperatures [65]. Environments that are hot enough to induce increases in body core temperature are consistently reported to adversely affect task performance [62,99,121,122,123,124,125,126,127,128,129]. Hancock [62] suggested that cognitive performance decrements in heat were due to dynamic increases in deep body (core) temperature and proposed that any thermal environment that led to a rate-of-increase in core temperature of $0.22{ }^{\circ} \mathrm{C} / \mathrm{h}$ impaired (dual tasks), $0.88^{\circ} \mathrm{C} / \mathrm{h}$ degraded (tracking tasks) and $1.33^{\circ} \mathrm{C} / \mathrm{h}$ reduced (simple mental task) efficiency. This interpretation aligns with Ramzjou and Kjellberg's [130] report of a negative correlation between performance on both a simple reaction time task and a serial four-choice reaction time task, and the rate-of-change in core temperature.

Earlier studies of cold environments and cognitive performance have indicated that even moderate cold exposures can have a negative effect on cognitive function $[131,132,133]$. To be specific, cold exposures ranging from extremes of $-20^{\circ} \mathrm{C}$ up to a moderate $10{ }^{\circ} \mathrm{C}$ have led to statistically significant decrements in memory performance $[11,134,135,136]$, vigilance [137], reaction time [11,136,138,139], learning and reasoning [65,136], and decision-making [11,140]. However, there are also recent studies that have reported no change of vigilance or multiple-choice reaction performance at $0{ }^{\circ} \mathrm{C}[128]$, and no change of psychomotor vigilance, four-choice reaction time, match-to-sample efficiency, or grammar performance at $10^{\circ} \mathrm{C}[141]$.

\section{- Duration of Exposure}

Previously published research findings are inconsistent on the question of how duration of exposure to thermal stress affects cognitive performance. Ramsey and Kwon [142] as well as Ramsey [19] concluded that the duration of exposure to heat did not have influence on performance, but Pilcher et al. [65] concluded that performance deteriorated more under

\footnotetext{
${ }^{3}$ Effective temperature (old ET): the first version of the ET environmental index that combines the comfort effects of both temperature and humidity. Because of the transient comparative exposures in the ET index's underlying chamber experiments, ET tends to over-emphasize the comfort significance of humidity relative to steady-state exposures.

${ }^{4}$ The effect size statistic represents how many standard deviations the mean dependent variable score for the experimental group differed from that of the control group.
} 
short-term temperature exposures compared to prolonged exposures, while Hancock et al. [10] and Yeganeh et al. [143] reported completely the opposite, with greater decrements in cognitive performance during prolonged exposure to thermal stressors. Hancock et al. [10] claimed that this relationship broke down in the very longest time intervals exposures lasting longer than $3 \mathrm{~h}$ were as benign as exposures shorter than $1 \mathrm{~h}[10]$. However, the same researchers also reported an interaction effect between duration and intensity of heat exposure: thus, a shorter exposure to heat results in greater performance degradation compared to longer exposures, implying some form of habituation to heat (discussed later).

Inconsistent duration of exposure effects could be partly due to the diverse task types under investigation. López-Sánchez and Hancock [68] reported distinct task-specific patterns of performance deterioration linking temperature and exposure time, e.g. for the same probability of impaired performance represented by isodecrement curves, mental and vigilance tasks demonstrated more prominent temperature effects on exposure time in high temperatures than more comfortable temperatures.

\section{- $\quad$ Thermal transients}

A handful of studies have examined cognitive performance under transient thermal exposures - temperature ramps, drifts and cycles [38], and they have reported contradictory findings. Studies by Wyon et al. [144,145] and Zhang and de Dear [115] are the only studies focused on the cognitive performance during environmental temperature cycles. The Wyon et al. [145] climate chamber study of 16 participants found that small, rapid swings around the preferred temperature resulted in decreased efficiency and speed of mental arithmetic, while larger amplitude, slower swings were associated with higher work speed and accuracy at least equal to that obtained under steady-state exposures. In contrast, the larger climate chamber study of 56 participants by Zhang and de Dear [115] failed to detect any such statistically significant difference in university students' memory, concentration, reasoning or planning performance during exposure to temperature cycles of various amplitude and frequency.

Nor have previous laboratory studies on moderate temperature ramps yielded any consistent findings on cognitive performance $[146,147,148]$. In a $1.5{ }^{\circ} \mathrm{C}$ rising temperature ramp over a $2.5 \mathrm{~h}$ interval, Newsham et al. [146] reported that some tasks such as solving anagrams, evaluating resumes, and vigilance exercises were negatively affected, whereas satisfaction of performance, time taken to rate magazines, motivation and short-term memory were all improved during exposure to the same temperature ramp. Kolarik et al. [147] investigated the effects of different temperature ramps ranging between $17.8-26.8^{\circ} \mathrm{C}$ on office work performance, and found that individuals read more quickly but detected slightly fewer mistakes while proof-reading under the rising temperature ramps. In contrast, downward temperature ramps positively influenced reading speed, accuracy, as well as comprehension. In contrast Schellen et al. [148] examined the effects of similar moderate temperature ramps $\left(17-25^{\circ} \mathrm{C}\right)$ on younger and older adults' text typing and arithmetic addition performance, but failed to detect any significant effect in either age group of subjects.

Muller et al. [11] investigated the effects of large temperature step changes $\left(25 \longrightarrow 10 \rightarrow 25^{\circ} \mathrm{C}\right)$ on cognitive performance and found significant decrements in working memory, choice reaction time, and executive function during the cold exposure $\left(10^{\circ} \mathrm{C}\right)$. Moreover, these impairments did not disappear until 60 min after the $25^{\circ} \mathrm{C}$ rewarming period started.

\subsubsection{Task-related Factors}

- $\quad$ Task Type

There is broad consensus that the impact of heat stress on cognitive performance is highly task dependent, with simple tasks that require less attention being less susceptible to heat effects than more complex tasks $[9,10,19,57,65,100,120,143,149,150,151]$. For example, studies using functional Magnetic Resonance Imaging (fMRI) to examine the brain activities found that passive heat exposures ( $45-60 \mathrm{~min}$ at $50{ }^{\circ} \mathrm{C}, 40 \%$ relative humidity) did not affect the performance of simple mental tasks such as alerting and orienting, but complex executive function, especially the efficiency of resolving conflict was adversely affected [152,153]. The mediating effect of task type for cold stress on cognitive performance has also been reported in a few studies showing varied performance threshold temperatures and patterns of response for different tasks [18,134,139,154,155], but further studies and validation are needed before definitive conclusions can be drawn. 
Previous reviews have often categorized performance studies into different types of tasks. Ramsey [19] proposed two broad categories: (1) mental, cognitive, simple perceptual motor, sensory, time estimation, reaction time, and (2) other perceptual motor tasks including tracking, vigilance, vehicle or machine operation, complex or dual tasks. Pilcher et al. [65] categorized performance tasks into four groups: (1) reaction time tasks, (2) attention/perceptual tasks, (3) mathematical processing tasks, and (4) reasoning/learning/memory tasks. Hancock et al. [10] divided performance tasks into three categories, i.e., perception, psychomotor, and cognitive tasks.

Pilcher et al. [65] concluded that thermal environments have different effects on different types of tasks, with thermal environments higher than $26.7^{\circ} \mathrm{C}$ WBGT $\left(29.0^{\circ} \mathrm{C}\right.$ at $\left.50 \% \mathrm{RH}\right)$ having the greatest negative impact on attentional/perceptual tasks and mathematical processing, whereas cold stress below $18.3^{\circ} \mathrm{C}$ WBGT $\left(20.2{ }^{\circ} \mathrm{C}\right.$ at $\left.50 \%\right)$ negatively affected reasoning/learning/memory tasks the most. Hancock et al. [10] concluded that cognitive performance was generally more stable under thermal stress conditions compared to perceptual and psychomotor performance, and that cognition could actually benefit from brief exposures to moderately cold temperatures.

Recent brain research also shows, that different cognitive functions are affected differentially by thermal stress. Gaoua [16] pointed out that different cognitive tasks activate different regions of the brain [156,157]. Recent animal researches $[156,158]$ have reported brain temperature fluctuations of $3-4{ }^{\circ} \mathrm{C}$ during different naturally occurring physiological and behavioural activities even at static thermal environments. For example, resting rats have significantly lower hippocampus temperature (about $0.7^{\circ} \mathrm{C}$ ) compared to the medial pre-optic area of the hypothalamus [158]. Temperature of both brain areas is directly correlated with core temperature and increases in a linear fashion [158]. This means at the same core temperature, different brain areas would have different absolute thermal load, which is to say, thermal stress could potentially affect cognitive capacity to varying degrees depending on the specific brain areas being engaged [16].

- $\quad$ Task Complexity

Cognitive tasks have often been characterised as either "simple" or "complex", but even this seemingly straightforward categorization has proven to be controversial and problematic [157]. Taylor et al. [66] provided a list of cognitive tasks (see Table 2) that are generally agreed to be either simple or complex, based on a survey of the literature $[9,16,142,159,160]$ but then issued the caveat that such classifications should be interpreted with caution. Gaoua [16] pointed out that previous literature conflated "task type" and "task complexity" into one categorization. This differentiation tends to ignore the differential cognitive loads exerted on respective brain regions. It was therefore suggested that future work should look at both task type as well as complexity by manipulating complexity within the same types of task [16].

Table 2 Categorization of simple and complex cognitive tasks [66]

\subsubsection{Performer-related Factors}

- Skill Levels of the Performer

Researchers from diverse domains generally agree that performers of a higher skill level prove less susceptible to performance decrements under thermal stress (e.g. $[9,16,19,62,66,142,161])$.

According to cognitive load theory (CLT) of instructional design [162,163,164,165,166,167,168,169], cognitive architecture comprises Long-Term Memory (LTM) and Working Memory (WM), with the latter being severely limited in both capacity $[170,171,172]$ and duration [173]. When dealing with novel information, limited WM resources often fail to meet the demands of complex cognitive tasks. However, once the new information has been assimilated, processed, rehearsed, and stored in LTM, the constraints arising from limited WM resources are largely eliminated. Newly acquired information in LTM must be processed consciously and with considerable effort, but with increasing practice and familiarization, this information can be used with diminishing conscious processing effort, and finally, automatically $[174,175,176]$. With this automated processing, cognitive tasks can be carried out virtually unconsciously without the need of mental effort, further reducing the load on WM and the limitations of WM ultimately disappearing altogether for the most experienced performers working from previously learned information stored in LTM. 
- Gender and Age

Hancock and Vasmatzidis [9] emphasized the importance of gender when investigating thermal effects on cognitive performance. Methodological shortcomings notwithstanding, previous studies seemed to suggest that females' performance was generally less vulnerable to thermal stress than males'. Wyon et al. [177] observed a significantly slower response speed in male participants' multiplication task performance at $28{ }^{\circ} \mathrm{C}$ compared with either lower or higher temperatures, while female participants' performance on the same task was unaffected at $28^{\circ} \mathrm{C}$. Tanabe and Nishihara [107] reported no significant difference in females' performance in typing, addition, cursor positioning and Walter Reed Performance Assessment Battery Test at operative temperatures of $25.5^{\circ} \mathrm{C}, 28{ }^{\circ} \mathrm{C}$ and $33{ }^{\circ} \mathrm{C}$, but their male participants' typing performance at $25.5^{\circ} \mathrm{C}$ was significantly lower than at $28{ }^{\circ} \mathrm{C}$ and $33{ }^{\circ} \mathrm{C}$, and their performance of the "four choice serial reaction time" test at $33{ }^{\circ} \mathrm{C}$ was significantly lower than at $28^{\circ} \mathrm{C}$.

Drag and Bieliauskas' [178] review indicates that aging is associated with progressive decline of certain cognitive functions, such as processing speed [179,180], complex attention [181,182], executive functions [183,184], language [185,186], episodic memory [187], source memory [188], prospective memory [189], and visuospatial functioning $[190,191]$. However, there is no research evidence demonstrating that thermal environment affects cognitive performance of young or elderly adults differently. In a controlled trial, Trezza et al. [192] found that memory, attention and processing speed of 68 healthy, elderly adults (mean age 73 years, $69 \%$ female) exposed to a hot environment with air temperature of $32{ }^{\circ} \mathrm{C}$ was not significantly different from that observed during exposure to a neutral air temperature of $24^{\circ} \mathrm{C}$. This null finding aligned with that of Schellen et al. [148] who noted that the typing and addition performance of the elderly was not significantly different during a constant temperature of $21.5^{\circ} \mathrm{C}$ compared with a temperature drift ranging between $17^{\circ} \mathrm{C}$ and $25^{\circ} \mathrm{C}$. The null effects are those that would be predicted by the extended-U model.

\section{- Thermal Acclimatization}

Several previous studies have demonstrated that in hot environments, acclimatization to heat improves the efficiency of thermal physiological response of sweating and shortens onset time [193,194,195,196,197], with the net effect of averting core temperature excursions. However, effects of acclimatization on cognitive performance have not been sufficiently investigated, mainly because it is uncommon for cognitive performance studies in heat to report participants' state of acclimatization [10,19]. Radakovic et al. [198] studied the impacts of both active and passive acclimatization procedures on participants' physiological and cognitive responses during heat stress, and found no effect on attention tasks, however response accuracy in complex tasks was reduced for participants with no acclimatization. Gaoua [16] has pointed out that habitual acclimatization does not seem to be an important confounder when investigating cognitive performance in heat, unless a specific acclimatizing procedure is being implemented.

- Hydration Status

Mixed findings have been reported concerning the role of hydration status in thermal effects on cognitive performance. Decrements in cognitive processing have been associated with dehydration beyond 2\% [151,159,199,200,201,202], yet others have reported no meaningful impact $[141,203,204,205,206]$. Despite this, it would be prudent for the hydration status of all participants to be recorded in future thermal performance studies.

\subsubsection{Interactions between Environment, Task and Performer}

\section{- Core Temperature, Skin Temperature and Thermal Comfort}

The performers' core temperature, skin temperature, and thermal comfort/discomfort result from complex interactions between their thermal physiological responses, their behaviour, and their immediate physical environment. As noted earlier, dynamic increases in deep-body (core) temperature are thought to impair cognitive performance [15] but more recent studies have demonstrated that accompanying changes in skin temperature are also implicated $[16,66,207,208]$. In the Gaoua et al. study [208] participants were exposed to a room temperature of $50{ }^{\circ} \mathrm{C}$ at $30 \% \mathrm{RH}$ for up to $15 \mathrm{~min}$, resulting in a significant increase in skin temperature of up to $3{ }^{\circ} \mathrm{C}$, but core temperature remained unchanged. It was found that simple tasks were unaffected, whereas complex cognitive task performance significantly deteriorated during these brief exposures to heat. Increasing skin temperature was interpreted as a mediating physiological variable that alters the subjective state of an individual and impairs effective decision-making. In a similar experimental design, Gaoua et al. 
[207] applied cold packs for head cooling and found that some of the complex cognitive functions were preserved unchanged while other studies reported inconsistent effects of head cooling on cognitive performance [127,129,209].

The sensitivity of complex cognitive function to changes in skin temperature and thermal comfort/discomfort could be related to the alliesthesial effect, initially proposed by Cabanac [210] and subsequently developed by de Dear [211] and Parkinson and de Dear [212] into a conceptual model of dynamic and local thermal comfort. Any environmental stimulus that reduces load-error on the thermoregulatory system, or any of the body's other homeostatic systems, will be pleasantly perceived - positive alliesthesia. Conversely any environmental stimulus that enlarges load-error on the thermoregulatory system is perceived as an unpleasant stimulus - negative alliesthesia. Several transient thermal comfort studies aligned with the Gaoua et al. findings [207,208]. For example, Zhang and de Dear [115] reported a negative correlation between planning performance (complex cognitive task) and rate of environmental temperature increment, as well as a positive correlation between performance on the same cognitive task and thermal acceptability during environmental temperature cycles that started from $24^{\circ} \mathrm{C}$ (temporal alliesthesia). Schiavon et al. [117] found that the negative impacts of elevated environmental temperatures $\left(29^{\circ} \mathrm{C}\right)$ on cognitive performance were ameliorated when subjects were given access to a desk fan that they could control (spatial alliesthesia). These experimental studies, albeit limited in number, are consistent in their suggestion that both the spatial and the temporal variants of positive thermal alliesthesia can ameliorate the negative impacts of thermal stress on the performance of complex cognitive tasks. This begs the question as to whether negative alliesthesia may exacerbate performance decrements, but this has not yet been addressed in the thermal environment and performance literature. What is promising is that these results encourage the idea that technologically simple and affordable Personal Comfort Systems (PCS) $[213,214,215,216]$ may be feasible in preserving both comfort and cognitive efficiency across a range of moderate thermal environments.

- Other Interaction Effects

Mental effort can be assumed to reflect the interaction between the performer and the task characteristics, serving as an important mediating factor. Intuitively we know how strong motivation and mental effort can override the effects of stress on our performance even in extreme environmental conditions, and there is plenty of experimental evidence demonstrating this in the thermal environmental performance literature (e.g. $[9,57,58,101,217,218])$. Other interactive effects such as task type and exposure duration, task type and intensity of thermal stress, to mention just a few, may also influence both the magnitude and direction of thermal stressors on performance $[9,10]$.

\subsection{Causal Mechanisms Behind the Two Models}

The underlying mechanisms for changes in cognitive function during exposure to uncomfortable thermal environments are not yet fully understood, but numerous reviews across various disciplines have offered hypotheses and rationales (e.g. $[9,10,15,19,161,166,167,219,220])$.

The underlying rationale for the inverted-U model can be likened to Environmental Determinism Theory (EDT) prevalent in social ecology. Environmental determinism asserts that "human activity, culture, and physical and mental characteristics are, at once, informed and inhibited by the geographical and climatic conditions of the physical environment" ([221], p.720). For example, one of its earliest origins - the treatise "airs, waters, and places", claims that people's health, personality and physique are dependent on how the physical environment affects their bodily humors, i.e. blood, yellow bile, black bile and phlegm which regulate mood, temperament and physical well-being. The European understandings of environmental influences on human beings have been deeply influenced by this Hippocratic notion [221]. By analogy, the inverted-U model assumes that thermal environment and thermal stress directly determine the task performers' cognitive efficiency, regardless of other factors, and this reduces to a dose-response relationship [56]. However, this assumption oversimplifies the complex, dynamic and integrated "internal" mechanisms of human response to environmental stimuli. From an environmental ergonomist's angle, Parsons ([15], p.582) pointed out that “... the human body is not a passive system that responds to an environmental input in a way that is monotonically related to the level of the physical stimulus. Any response depends upon a great number of factors." He further elucidated three layers. First, if viewed in engineering terms, the "transducers" of the body - the human sensory organs such as eyes, ears, etc.each have their own specifications and response characteristics when stimulated by their relevant physical environmental element. Second, human bodies are not passive systems, but rather react homeostatically, constantly adjusting and regulating their physiological systems and behaviours to adapt to the environment. Third, the way people perceive and 
respond to environmental stimuli depends on many other factors such as their previous experience, expectations, cultural context, current emotional states, to mention just a few, and these are both inter-individual differences (e.g. gender, age, personality) and intra-individual differences (e.g. acclimatization, emotional state). Parsons' perspective intersects with Hancock's view [222] that engineering approaches regard building occupants as if they are insensate objects and "while simple linear equations describe heat exchange, they do not capture the subtlety and nuances of behavioural regulation, the prime goal of which is the maintenance of comfort" ([222], p.1860). The importance of behavioural regulation in achieving thermal comfort is also emphasized by the adaptive comfort theory [223,224], which deems the building occupants as being interactive agents in a person-environment system via multiple feedback loops including behavioral adjustment, physiological acclimatization, psychological habituation, and probably most important of all, expectation adjustment.

Not surprisingly, many researchers in the field of psychology have levelled criticisms at arousal theory and the inverted$\mathrm{U}$ model as an explanation of the relationship between stress and performance (e.g. [93,94,225,226,227]). The main arguments fall into two categories: first, Yerkes and Dodsons' original experimental study [95] was about animal learning, and the researchers themselves connected none of their observations with stress and performance. Second, the inverted-U relationship is an over-simplified, fundamentally flawed proposition, and the unitary arousal notion is incongruent with known physiological and psychological effects, and emerging behavioural response data (e.g. $[228,229,230,231,232])$. And yet, despite these glaring theoretical shortcomings, Arousal Theory continues to be taught as a fundamental "law" in psychology and the broader realms of human behaviour research: from product development teamwork [233] to the piloting of aircraft [234], from competing in sport [235] to solving complex cognitive puzzles [236].

The mechanisms underlying the extended-U model are well elaborated by the "cognitive load" construct from the Cognitive Load Theory (CLT) of instructional design (e.g. [161,166,167,237,238]). In CLT the physical environment, task, and performer are considered to be three causal factors pertaining to cognitive load, which is also affected by twoway and three-way interactions between the three factors. The construct of cognitive load is schematically presented in Figure 6. The major determining characteristics of environments, tasks, and performers, along with key interaction effects have been briefly discussed here. With regard to its assessment, cognitive load can be conceptualized into three dimensions, namely mental load, mental effort, and performance $[161,166]$. Mental load is a task-centered, subjectindependent dimension. Mental effort reflects performers' internal reaction to the mental load, such as their internal goals, motivation level and so on. As previously discussed, novel information in WM or newly acquired information in LTM must be processed consciously and with considerable mental effort, known as "controlled processing". "Automatic processing" happens when the requisite knowledge is well known and stored in the participant's LTM so that the task can be accomplished unconsciously without mental effort. Consequently, assessment of cognitive load based on mental effort reflects the amount of controlled processing in which the performer is engaged [174,175]. Performance is the output of the mental load and mental effort, and can also assess cognitive load.

Figure 6 Mechanism behind the extended-U model applied to relationships between thermal environments and cognitive load: thermal environment serves as one of the causal factors of cognitive load (modified after [161])

As have been discussed in Section 4.2, environmental stress may increase cognitive load by competing and consuming limited attentional resources, which could have been alternatively allocated to the task per se. Nonetheless, whether or not the performance is implicated still depends on other intervening factors. If the task induces low mental load, and there are sufficient attentional resources for both the task and the imposed environmental stress, performance efficiency will not be affected. Similarly, extra mental effort can cope with increased environmental stress in order to maintain the same level of performance; this extra effort will not be needed if the performer achieves automatic processing in carrying out the task. Besides, other environment-, task- and performer-related factors along with the two-way and three-way interactions (discussed in Section 5.1) may also mediate the effect of environmental stress on performance. 
In the human-machine-systems research domain there is an analogous concept to cognitive load, termed mental workload [219,239,240,241]. Johannsen [220] discussed the three functionally relatable attributes of mental workload and its assessment (as shown in Figure 7). These attributes echoed the assessment factors of cognitive load in CLT illustrated in Figure 6. Input load can come from three major sources: environment (such as temperature, noise, smell); design and situation (e.g. characteristics of display and control devices); and procedures (e.g. task sequence, task duration, etc.). Operator effort is determined by the input load, characteristics of the performer, and the requirements of the given task. The performer characteristics can comprise many factors ranging from relatively stable ones such as psychophysical characteristics, general background and personality, through to fluctuating ones such as experience, motivation, and attentiveness [219].

To sum up, both the CLT theory and Mental Workload theory confirm that the physical environment serves as one factor that induces cognitive load (mental workload), but there is not a dose-response relationship between environment and performance due to many intervening factors.

Figure 7 Assessment of mental workload by input load, operator effort and performance [219,220]

\subsection{Methodological Discrepancies}

As Hancock and Ganey [93] have pointed out, the enduring popularity of the inverted-U relationship as an explanation of the effects of stress on performance resides in its intuitive appeal, aligning with "common sense" interpretations of the issue. Nevertheless there are methodological shortcomings that weaken, if not invalidate the empirical evidence adduced to support the inverted- $\mathrm{U}$ model in the indoor environmental science and engineering literature.

\subsubsection{Three Primary Approaches to Measuring Cognitive Load}

Previous researchers [242,243,244,245] have identified three fundamentally different approaches to the measurement of cognitive load: (1) primary task performance; (2) subjective perception of cognitive load; (3) physiological response, but studies where they have been used alongside one another indicate divergence.

- $\quad$ Primary Task Performance

Primary task performance (Figure 7) has been expressed variously as by probability of error, response time, response accuracy, response consistency, and response range, but speed and accuracy are the most commonly used forms of assessment, particularly in field-based research (see e.g. [13,246,247]). Lan et al. [53,248] pointed out that in indoor environmental science research, response speed is used more often than response accuracy to quantify performance. For many types of tasks there exists a speed-accuracy trade-off [248,249]. Hancock et al. [10] concluded that heat affects response time and accuracy differently: no matter the heat is above or below the $29.4{ }^{\circ} \mathrm{C}$ old ET threshold, response accuracy will be uniformly affected by heat stressors; as a contrast, no effect for heat on response time has been observed below the threshold. Yeganeh et al. [143]'s meta-analysis generally corroborate Hancock's finding that response accuracy is more affected by heat than response time.

- $\quad$ Subjective Perceptions of Cognitive Load

The concomitant changes in mental effort (Figure 6) might not be self-evident in work performance measurements since people tend to adjust to changes in task demands in ways that protect their performance [218]. In this case, self-reported perceptions can be helpful. Commonly used subjective measurements of cognitive load include NASA-TLX and SWAT. NASA Task Load Index (TLX) relies on a multidimensional construct to generate an overall workload score according to weighted average ratings on six subscales: mental demand, physical demand, temporal demand, performance, effort, and frustration level [250]. The Subjective Workload Assessment Technique (SWAT) described by Reid and Nygren [251] also requires participants to rate the workload of a task, but uses a different suite of rating dimensions: time load, mental effort load and psychological stress load. Parsons [15] pointed out that subjective ratings are easy to implement and well suited to the assessment of psychological responses. They can also be useful when the contributing factors to a response 
are unknown. However, subjective ratings are often not appropriate for assessing effects on health since the environmental stressor can also interfere with the capacity to make a reliable subjective assessment.

\section{- Physiological Responses}

Due to the development of brain imaging technologies in recent decades there are many new approaches that visualize brain activities and directly measure the physiological responses under mental workload, including electroencephalogram (EEG) [252], heart rate and heart rate variability [253]. Employing these measures leads to a better understanding of the neural architecture of cognitive abilities.

The raw electroencephalogram, or background EEG, is indicative of brain activity levels [254]. Liu et al. [153] and Sun et al. [255] adopted functional Magnetic Resonance Imaging (fMRI) to examine alterations of the brain blood flow and how different environmental conditions affect attention network. Functional Near-Infrared Spectroscopy (fNIRS) provides safe and continuous monitoring of changes in both blood oxygenation and volume that are related to human brain function. Compared to other neuroimaging techniques such as EEG and fMRI, fNIRS is a good compromise between spatial and temporal resolution. fNIRS has a higher spatial resolution than EEG, and is less susceptible to motion-related artefacts, blinking or eye movements, compared to EEG [256]. Previous studies reveal that physical and mental workload has a clear impact on Electrocardiography (ECG), or heart rate and heart rate variability

$[257,258,259,260]$. Increased heart rate and decreased heart rate variability are usually associated with mental exertion [261].

It is worthwhile noting that the above three approaches of cognitive load measurement $—$ primary task, subjective perceptions and physiological responses, do not always agree with each other when they are applied concurrently. As has been observed by Hancock et al. [245], results from the three approaches could agree with each other (association), or may not correlate (insensitive), or contradict each other (dissociation), with each circumstance commonly being reported in different research studies [262]. For example, Lan et al. [58] adopted all three approaches in evaluating the effects of temperature on cognitive load. The primary task results were not significantly different between various temperature conditions of their experimental design, yet the participants' subjectively rated cognitive load was higher in the moderately uncomfortable environment, and their EEG and ECG results displayed significant differences between comfortable and warm conditions. Conflicted responses often leave researchers in a methodological quandary as to which approach and corresponding results to trust and to report, and which, if any, to ignore without appearing to "cherry-pick" the data [245]. The interpretation of results from divergent cognitive load measures has undoubtedly contributed to the contradictory conclusions throughout the literature. For example, the meta-analyses conducted by Pilcher et al. [65] and Hancock et al. [10] only included primary task performance results, expressly precluding papers based on subjective ratings and physiological measurements. This uniformity of cognitive load measurement in their meta-analyses goes some way towards explaining why they found relatively stable performance across a wide range of thermal environments. In the indoor environment area, researchers tend to put greater emphasis on perceived performance and subjective ratings as opposed to objective performance metrics (e.g. $[57,58,109,111])$. Despite their objective performance measurements failing to show any significant difference between exposure temperatures, Witterseh et al. [108], Lan and Lian [111] and Lan et al. [53] focused their interpretation on subjective ratings such as self-estimated performance, emotional state, motivation level, health symptoms, well-being, and perceived mental workload. They concluded that "office work may generally be performed considerably less well in ... and less well at subjectively warm air temperatures than at cooler temperatures" ([108], p.39), “... the performance of neurobehavioral tests decreased when the thermal environment deviated from neutral condition" ([111], p. 2208), and "... thermal discomfort caused by high or low air temperature had negative influence on office workers' productivity"([58], p.36). The issue of exactly how to filter and interpret cognitive load data from different approaches falls outside the scope of this review, but it seems fairly obvious that it should take at least some of the blame for the inconsistencies plaguing the literature on thermal effect on cognitive performance.

\subsubsection{Plethora of Cognitive Task Types and Levels of Complexity}

The performance results used in the meta-analysis by Seppänen and Fisk [50] as well as Seppänen et al. [52] were drawn from a variety of environments, including call centres, apparel factories, classrooms, offices, laboratories, to mention just a few, and the performance metrics included the number of customer service calls per hour in the case of the call centre 
studies, rate of sewing piece-work, learning, text typing speed and error rate, error detection in proofreading, arithmetic addition, creative thinking, letter searching, number searching, memory tests, and vigilance tasks. The metrics spanned the gamut of human performance domains - manual, reaction time, attention, perceptual motor, mathematical processing, reasoning, memory, and executive function. As noted earlier, the magnitude of performance decrements under heat or cold stress, and the temperature thresholds at which they occur, depend on both the type and complexity of the cognitive task in question. Consequently pooling performance data from diverse cognitive tasks (e.g. [50,52,53,57,83,84,100,111]) seems likely to have contributed to both the confusion and the contradictory conclusions across the literature on thermal effects on cognitive performance in the indoor environment.

\subsubsection{Statistical Analyses}

Another potential explanation for discrepancies between stress-performance models is divergent analytical approaches adopted by different researchers. For example, Seppänen et al. [52] indicated that some studies in their meta-analysis relied on multiple performance tests from each subject, and so results might be highly correlated. Despite acknowledging that the assumption of independence of errors was violated, Seppänen et al. [52] conducted simple regression analysis on repeated-measure data to develop a performance-temperature relationship, as have several other researchers in this domain. They typically developed a cubic or quadratic relationship (Equation (1)) between performance and temperature (or thermal sensation), speciously supporting the inverted-U model $[53,55,56,83,100,101,111,263,264]$.

$R P=a T S V^{3}+b T S V^{2}+c T S V^{1}+d$

where $R P$ denotes relative performance and TSV is thermal sensation vote $(-3$ to +3 on the ASHRAE seven-point thermal sensation scale). Some studies use PMV (also on the ASHRAE seven-point scale) or air temperature as the predictor.

There are two types of problems with this statistical analysis. First, analysing data sets containing hierarchical structures resulting from within-subject research designs, as if they are all on the same level, risks both interpretation and statistical errors [265,266]. In particular, if correlated or clustered data are analysed using a single-level model and there is dependence of errors, the risk of Type I error (rejection of a null hypothesis when it is actually true) can dramatically increase [267]. Therefore, findings of significant effects of treatment variable cannot be trusted when independence of errors has been assumed without justification [267,268]. Second, univariate regression as in Equation (1) with TSV or air temperature as the only predictor overlooks effects of other predictors (confounding variables) on cognitive performance such as subjects' age, sex, sequence effects, etc.

To conduct regression analysis with correlated or clustered data, it is recommended to use Generalized estimating equations (GEEs) or Generalized linear mixed models (GLMMs) [268]. The former approach focuses on estimating the average response over the population, while the latter approach can make inference about individuals [268]. GLMMs are also referred to as multilevel models, mixed models, random coefficient models, and hierarchical models [269]. To illustrate the effect of different statistical analytic strategies on the same set of performance data, we have re-analysed the results reported in Experimental 1 of Zhang and de Dear [115] using (a) single-level univariate regression analysis as shown in Equation (1), and (b) the more appropriate multilevel models with significant sequence effects adjusted. The analysis (a) yielded a statistically significant quadratic regression model between reasoning performance score and thermal sensation vote ( $\left.p=0.031, \mathrm{R}^{2}=0.015\right)$ - so the research hypothesis is mistakenly accepted. In contrast, when the same data are reanalysed with multilevel models with sequence effects adjusted (b), no significant relationship was detected (shown in Zhang and de Dear [115] Table 5: Reasoning skills) — so the null hypothesis is correctly accepted.

\subsubsection{Construct Validity/Sensitivities of the Performance Tests}

Variations in construct validity and sensitivity of performance tests may also have contributed to contradictory research results being reported in the temperature-performance literature. There are two major types of problems, the first having been mentioned earlier in relation to Figure 6, refers to working memory (WM) being in short supply. But constraints of WM are eliminated when the task's requisite knowledge and skills are well rehearsed and residing in long term memory (LTM). Therefore the performance tests adopted in temperature-performance research should primarily place demands on WM rather than LTM; otherwise these tests may not be sensitive to the physical environment. Sensharma et al. [47] also emphasized that performance measures must be measurable and controllable, meaning they must be sensitive and 
responsive to changes in the indoor environment. Reading comprehension and proof reading have commonly been used as cognitive performance tests in the indoor environment research domain (e.g. [108,109,110,111,147,263,270,271]), yet less common in other domains of performance research. Performance in these tests depends primarily on participants' intrinsic language skills which reside in their LTM rather than their cognitive skills located in WM. Consequently, when tested in various thermal environments, expert language users may experience little or no change of performance, whereas subjects with weaker language proficiency may be more adversely affected by thermal environmental stress. The final result may be predicted by the composition of the test sample - if there are high skill levels in the sample, performance may not be significantly affected, and vice versa.

Another potentially complicating issue is that a valid productivity measure may not be a valid cognitive load/performance measure for testing environmental impact. As discussed in Section 3, productivity involves many factors other than performance itself, thus a productivity measure may not be strictly appropriate for testing the effect of thermal environment on performance. Previous studies in call centres have adopted the average time per call or the number of calls handled during active working hours as productivity measures [85,272,273,274] for testing the impacts of thermal environments. Indeed, the average handling time is an important index for call centre productivity, but apart from the thermal environment, the handling time to serve a customer could also be influenced by many other factors including the nature and complexity of the queries, the standardized work process of call centres, the interaction between customers and service staff, personality and emotional state of the staff [73]. These factors almost certainly would have contributed to the significant changes in call centre productivity observed in those studies.

\section{Implications of Different Models for Indoor Thermal Environmental Control and Building Energy Use}

The range of indoor temperatures deemed acceptable by occupants has a strong bearing on building energy requirements because it constrains the geographic scope as well as the seasonal duration when passive design approaches are able to achieve acceptable indoor environments. Secondly, the indoor design temperature range indoors directly impacts energy required by active systems (HVAC) to achieve them. The most significant implication of the controversy over the inverted- $U$ versus the extended- $U$ models of thermal environmental effects on performance relates to the management of indoor environment of commercial premises [214,215]. The two models have diametrically opposed implications for the design and operation of indoor climate and associated energy requirements. The concept of a single-temperature optimum implied by the inverted-U model encourages facility managers to specify heating and cooling setpoints as close together as technology permits. In particular, the appearance of the single optimum model in ASHRAE Handbook of Fundamentals [27] (Figure 3) has contributed to the propagation of energy intensive control practices worldwide. Many countries such as Australia have gone as far as embedding tight thermal control clauses in commercial office space lease agreements $[37,116]$ in the mistaken belief that the value of "lost" productivity resulting from temperature variations will grossly outweigh the energy costs of tight control (e.g. [46,51,71,111,275,276,277,278,279]). However, the analysis in the current paper casts doubt on simplistic dose-response relationships between temperature and cognitive performance, not to mention the more abstract construct of office productivity. The cost-benefit analysis is flawed on both sides of the ledger: the value of calculated productivity "losses" is questionable and the energy penalty of operating narrow control deadband are non-trivial because cooling systems are deployed intermittently to offset overheating and vice versa [214]. In effect, the widespread overcooling of commercial buildings in developed countries has incurred heavy energy, environmental and financial costs. Derrible and Reeder [30] has calculated the cost of over-cooling commercial buildings in US, 2012 to be $103,929 \mathrm{GWh}$ for the energy cost, 57,125 $\mathrm{kt} \mathrm{CO}_{2}$ for the environmental cost, and US\$10 billion for the financial cost. Using World Bank data [280] to put these estimates into perspective, 103,929 GWh is slightly more than the total electricity consumption of Belgium in 2011 while $57,125 \mathrm{kt} \mathrm{CO}_{2}$ is equivalent to the total greenhouse gas emissions by Norway in 2010, and ten billion US dollars represents the entire gross domestic product (GDP) of Mongolia (2012 value). In addition, a significant externality overlooked in this simplistic temperature-productivity calculus is the increment in greenhouse gas emissions associated with tight setpoint temperature deadband control strategies [263].

The extended-U model is accompanied by a theoretically coherent explanation of temperature effects on cognitive performance. Due to the wide range of intervening factors at play (as discussed in Section 5.1), occupants' cognitive performance remains in dynamic equilibrium under moderate levels of environmental stress, including thermal stress, 
until adaptive resources or the "cognitive reserve" of the subject are depleted. As depicted in Figure 5, the central plateau area near optimal cognitive performance goes beyond the comfort zone, although the threshold may vary for different environment-, task- and performer-related factors. Implementation in facility management practice for indoor thermal environmental control, if performance is given priority, permits indoor temperatures to extend into the moderate thermal discomfort zone. But when thermal comfort and cognitive performance requirements are combined, it would be prudent for heating setpoints to align with the lower boundary of the comfort zone, and likewise cooling setpoint should align with the comfort zone's upper boundary [38], or perhaps marginally further during electricity peak demand events [35]. Use of PCS hold promise for further extending the thermostat setpoint range beyond the comfort zone while still maintaining high levels of occupant thermal satisfaction [214,216,281,282].

In contrast to the waste of energy dictated by the inverted-U function, widening the thermostat setpoint range by implementing the extended-U model will lead to substantial savings in building HVAC energy. Previous researches have carried out simulation studies on the effect of wider HVAC thermostat deadband on the building energy consumption. Hoyt et al. [214] performed a dynamic thermal simulation study on the effects of wider thermostat setpoint ranges on annual HVAC energy requirements of typical, medium-sized office buildings in seven US climate zones. Compared with the baseline deadband range of $21.1-22.2^{\circ} \mathrm{C}$ commonly practiced in many parts of the world, elevating the cooling setpoint from $22.2{ }^{\circ} \mathrm{C}$ to $25{ }^{\circ} \mathrm{C}$ while maintaining heating setpoint at $21.1{ }^{\circ} \mathrm{C}$ results in an average of $29 \%$ reduced cooling energy and $27 \%$ of total HVAC energy savings. Reducing the heating setpoint from $21.1^{\circ} \mathrm{C}$ to $20^{\circ} \mathrm{C}$ while maintaining the cooling setpoint at the default $22.2{ }^{\circ} \mathrm{C}$ yields an average of $34 \%$ heating energy savings. Adoption of PCS devices can further enlarge the deadband to $18.3-27.8^{\circ} \mathrm{C}$, which equates to $32 \%-73 \%$ of HVAC energy saving, depending on the climate zone. Similarly, Ghahramani et al. [283] studied the interrelationships between thermostat setpoints, deadbands and several other factors and concluded that HVAC deadband of $0,1,2,4,5$, and $6{ }^{\circ} \mathrm{C}$ would result in an average energy savings of $-70.0 \%,-34.9 \%,-13.7 \%, 9.6 \%, 16.4 \%$, and $21.2 \%$, respectively, compared to the baseline deadband of $3{ }^{\circ} \mathrm{C}$. Daily optimal setpoint in the range of $22.5 \pm 1{ }^{\circ} \mathrm{C}, 22.5 \pm 2{ }^{\circ} \mathrm{C}$, and $22.5 \pm 3{ }^{\circ} \mathrm{C}$ would result in an average savings of $7.5 \%, 12.7 \%$, and $16.4 \%$, respectively, compared to the baseline setpoint of $22.5{ }^{\circ} \mathrm{C}$.

\section{Conclusions}

For several decades the effect of thermal environment on performance has been a focus of research among indoor environmental scientists, but the work has been conducted and discussed in isolation from the broader domains of human performance science. In this paper we reviewed a collection of research publications, all specifically examining the effects of thermal environment on cognitive performance, but coming from a wide variety of disciplinary perspectives extending well beyond the usual indoor environmental sciences, including psychology, physiology, ergonomics, neuroscience, sports science, medical science, learning and instructional design, and human-technology interaction. Studies included static and transient thermal environmental exposures, extreme and moderate temperatures, and they reported inconsistent results ranging from cognitive performance decrements to null findings, and in some cases, even enhanced performance under moderate levels of thermal stress.

A plethora of confounding factors were identified as potential explanations of the inconsistencies. For example, Cognitive Load Theory contends that environment, task and performer are the three causal factors of cognitive load. The environment-related factors include intensity of thermal stress, duration of exposure and thermal transients. Performerrelated factors include gender, age, skill level, acclimatization status, hydration status, emotion state, personality, to mention just a few. Task-related factors include task type and complexity. Two-way and three-way interactions between the environment, task and performer can also mediate cognitive load.

Two competing models linking thermal environment and cognitive performance emerged from our multidisciplinary literature review: the inverted-U relationship and the extended-U relationship. The inverted-U relationship is premised on Arousal Theory and features a single optimum temperature for maximal cognitive performance. The extended-U relationship, on the other hand, features a broad plateau of temperatures in which cognitive performance remains relatively unaffected. The boundaries of the performance plateau are characterised by progressive performance decrements as thermal environmental conditions become more extreme. Although the inverted-U relationship has held sway in the indoor environment research literature and practice, many researchers have criticized its overly simplistic 
concept and methodologically flawed empirical bases. The unitary arousal notion is incongruent with known physiological and psychological effects, and emerging behavioural response data. It is implausible to characterise the human body as a simple linear transducer of environmentally imposed loads. The remarkable adaptability of our species enables us to absorb a range of externally imposed demands without any discernible decrement in performance.

Apart from confounding variables, methodological discrepancies between studies has no doubt lead to incompatible conceptual models: how to filter and report insensitive or dissociated data from three cognitive load measurement approaches can potentially cause confusion and controversy. Performance meta-analyses in the indoor environmental science literature have pooled results from diverse cognitive task types and complexity, each with their distinct performance decrement thresholds, and this has probably contributed to the glaring inconstancies prevalent in the literature. Furthermore, the adoption of single-level, univariate regression analysis in several studies applied to repeatedmeasures with potential confounders may have also contributed to some of the false-positive evidence adduced in support of the inverted-U model. Finally, the performance measures used in some of the studies supplying evidence to support the inverted-U model are of questionable construct validity.

According to the extended-U model, indoor thermal environments can be controlled much less stringently than is currently practised. Building occupants have sufficient cognitive reserve and are also able to behaviourally adapt to moderate thermal environmental loads across, or even beyond the comfort zone, in order to protect performance without substantive increments in psychological or physiological demand. Contrary to the inverted-U function that has incurred horrendous waste of energy, the extended-U relationship has huge potentials in building energy conservation. Therefore, facility managers and building service engineers need to recognise that indoor temperatures spanning the full range of thermal acceptability (comfort zone) are serviceable instead of blindly pursuing a speciously defined single-temperature optimum.

\section{Recommendations for Future Researches}

Based on the analyses in this reivew, the following recommendations can be made for further research into the effects of moderate thermal environment on cognitive performance:

1) The effect of thermal environment on cognitive performance should not be used as a proxy for the effect of thermal environment on office productivity. The latter requires different measures that should be targeted in future studies.

2) Future studies should take potential confounding variables into consideration. As a minimum, the values of mediating factors should be reported for the purposes of future meta-analyses.

3) Standardized cognitive performance tests that place demands on working memory should be adopted; performance thresholds of different task types should be separately reported. Tasks with differing levels of complexity should be tested within the same task type.

4) Effects of thermal transients on cognitive performance warrants further exploration, particularly in workplace settings, as a strategy for preserving cognitive function while reducing peak electricity demand as well as overall HVAC energy requirements.

5) Further comparison and interpretation of results from diverse cognitive load measures are required before a robust, standardized methodology for studying thermal effects on cognitive performance can be established.

\section{Acknowledgement}

This research did not receive any specific grant from funding agencies in the public, commercial, or not-for-profit sectors.

\section{Declarations of interest: none}

\section{References:}

[1] Tromp SW. Biometeorology: the impact of the weather and climate on humans and their environment (animals and plants). London: Heyden \& Son Ltd; 1980. 
[2] Huntington E. Civilization and climate. New Haven: Yale University Press; 1924.

[3] Vernon HM. The Influence of Hours of Work and of Ventilation on Output in Tinplate Manufacture. London: H.M. Stationery Off; 1919.

[4] Vernon HM. Fatigue and efficiency in the iron and steel industry. London: H.M. Stationery Off.; 1920.

[5] Farmer EM., Brooke RSC, Chambers EG. A comparison of different shift systems in the glass trade. London: H.M. Stationery Off; 1924.

[6] Vernon HM. An investigation of the factors concerned in the causation of industrial accidents. London: 1919.

[7] Vernon HM, Bedford T. The Relation of Atmospheric Conditions to the Working Capacity and the Accident Bate of Coal Miners. London: H.M. Stationery Off; 1927.

[8] Hancock PA, Szalma JL. Performance under Stress. Aldershot England: Ashgate Publishing; 2008.

[9] Hancock PA, Vasmatzidis I. Effects of heat stress on cognitive performance: the current state of knowledge. Int J Hyperth 2003;19:352-61.

[10] Hancock PA, Ross JM, Szalma JL. A Meta-Analysis of Performance Response Under Thermal Stressors. Hum Factors J Hum Factors Ergon Soc 2007;49:851-77.

[11] Muller MD, Gunstad J, Alosco ML, Miller LA, Updegraff J, Spitznagel MB, Glickman EL. Acute cold exposure and cognitive function: Evidence for sustained impairment. Ergonomics 2012;55:792-8.

[12] Kerslake DM. The stress of hot environments. New York: Cambridge University Press; 1972.

[13] Hocking C, Silberstein RB, Lau WM, Stough C, Roberts W. Evaluation of cognitive performance in the heat by functional brain imaging and psychometric testing. Comp Biochem Physiol A Mol Integr Physiol 2001;128:71934.

[14] Burton AC, Edholm OG. Man in a Cold Environment: Physiological and Pathological Effects of Exposure to Low Temperatures. Proc. R. Soc. Med., vol. 49, London: Edward Arnold Ltd.; 1956, p. 1061.

[15] Parsons KC. Environmental ergonomics: A review of principles, methods and models. Appl Ergon 2000;31:58194.

[16] Gaoua N. Cognitive function in hot environments: a question of methodology. Scand J Med Sci Sport 2010;20:60-70.

[17] Fox WF. Human Performance in the Cold. Hum Factors 1967;9:203-20.

[18] Enander A. Effects of moderate cold on performance of psychomotor and cognitive tasks. Ergonomics 1987;30:1431-45.

[19] Ramsey JD. Task performance in heat: A review. Ergonomics 1995;38:154-65.

[20] Harkouss F, Fardoun F, Biwole PH. Passive design optimization of low energy buildings in different climates. Energy 2018;165:591-613.

[21] de Dear R, Zhang F. Dynamic environment, adaptive thermal comfort, and cognitive performance. Proc. 7th Int. Build. Phys. Conf., Syracuse, NY, USA: 2018, p. 1-6.

[22] Fanger PO. Thermal comfort. Analysis and applications in environmental engineering. Copenhagen: Danish Technical Press; 1970.

[23] EN-ISO-7730. Moderate Thermal Environments- Determination of the PMV and PPD Indices and Specification of the Conditions of Thermal Comfort. Geneva: 2005.

[24] de Dear R, Brager G, Donna C. Developing an adaptive model of thermal comfort and preference. ASHRAE Trans 1998;104:145-67.

[25] de Dear R, Brager GS. The adaptive model of thermal comfort and energy conservation in the built environment. Int J Biometeorol 2001;45:100-8.

[26] Wargocki P, Seppanen O, Andersson J, Boestra A, Clements-Croome D, Fitzner K, Hanssen SO. Indoor climate and productivity in offices: How to integrate productivity in life cycle costs analysis of building services. 1 st ed. Brussels: REHVA; 2006.

[27] ASHRAE. 2013 ASHRAE handbook : Fundamentals. Atlanta: American Society of Heating, Refrigerating and Air-Conditioning Engineers, Inc.; 2013. 
[28] Brager G, Zhang H, Arens E. Evolving opportunities for providing thermal comfort. Build Res Inf 2015;43:27487.

[29] Gutierrez-->-Aliaga L, Williams E. Co-alignment of comfort and energy saving objectives for U.S. office buildings and restaurants. Sustain Cities Soc 2016;27:32-41.

[30] Derrible S, Reeder M. The cost of over-cooling commercial buildings in the United States. Energy Build 2015;108:304-6.

[31] Baniyounes AM, Ghadi YY, Rasul MG, Khan MMK. An overview of solar assisted air conditioning in Queensland's subtropical regions, Australia. Renew Sustain Energy Rev 2013;26:781-804.

[32] Lucon O, Ürge-Vorsatz D, Ahmed AZ, Akbari H, Bertoldi P, Cabeza LF, Eyre N, Gadgil A, Harvey LDD, Jiang Y, Liphoto E, Mirasgedis S, Murakami S, Parikh J, Pyke C, Vilariño MV. Buildings. In: Edenhofer O, PichsMadruga R, Sokona Y, Farahani E, Kadner S, Seyboth K, Adler A, Baum I, Brunner S, Eickemeier P, Kriemann B, Savolainen J, Schlömer S, Stechow C von, Zwickel T, Minx JC, editors. Clim. Chang. 2014 Mitig. Clim. Chang. Contrib. Work. Gr. III to Fifth Assess. Rep. Intergov. Panel Clim. Chang., Cambridge, United Kingdom and New York, USA: Cambridge University Press; 2014.

[33] Brager G, Baker L. Occupant satisfaction in mixed-mode buildings. Build Res Inf 2009;37:369-80.

[34] Mendell MJ, Mirer AG. Indoor thermal factors and symptoms in office workers: findings from the US EPA BASE study. Indoor Air 2009;19:291-302.

[35] Cao X, Dai X, Liu J. Building energy-consumption status worldwide and the state-of-the-art technologies for zero-energy buildings during the past decade. Energy Build 2016;128:198-213.

[36] Energy D of the E and. HVAC factsheet - Energy breakdown. HVAC HESS Heating, Vent Air-Conditioning High Effic Syst Strateg 2013:1-2. https://www.energy.gov.au/sites/g/files/net3411/f/hvac-factsheet-energybreakdown.pdf (accessed November 19, 2018).

[37] Roussac AC, Bright S. Improving environmental performance through innovative commercial leasing. Int J Law Built Environ 2012;4:6-22.

[38] ASHRAE. ASHRAE Standard 55: Thermal Environmental Conditions for Human Occupancy. Atlanta: American Society of Heating, Refrigerating and Air-Conditioning Engineers, Inc; 2017.

[39] Ward JK, White SD. Smart thermostats trial: Part 1, energy efficiency. AIRAH Pre-Loved Build. Conf. Contin. Push, Brisbane: 2007.

[40] LaBar G. Why Employees Are Sick of Indoor Air. Occup Hazard 1992;54:32-6.

[41] G. Lorsch H, A. Abdou O. Impact of the building indoor environment on occupant productivity - part 1: recent studies, measures, and costs. vol. 100. 1994.

[42] Lorsch HG, Abdou OA. The impact of the indoor environment on occupant productivity - Part 2 Effects of temperature. ASHRAE Trans 1994;100:895-901.

[43] Abdou O, Lorsch H. The Impact of the Building Indoor Environment on Occupant Productivity - Part 3: Effects of Indoor Air Quality. ASHRAE Trans., vol. 100. 2nd ed., 1994, p. 902-13.

[44] Abdou POA, Kholy GM El, Abdou AA, Abdou OA, El. Kholy GM, Abdou AA. Correlation between indoor environmental quality and productivity in buildings. 19th Int. Assoc. People-environment Stud., Alexandria: 2006, p. 1-15.

[45] Raw GJ, Roys MS, Lehman A. Further findings from the office environment survey: productivity. Indoor Air ' 90 , Fifth Int. Conf. Indoor Air Qual. Clim., Toronto: 1990, p. 231-6.

[46] Fisk WJ. How IEQ affects health, productivity. ASHRAE J 2002;44:56-60.

[47] Sensharma NP, Woods JE, Goodwin AK. Relationships between the indoor environment and productivity: A literature review. ASHRAE Trans 1998;104:686-701.

[48] Wyon DP. Indoor Environmental Effects on Productivity. Proc 7th Int Conf Indoor Air Qual Clim 1996:5-51.

[49] Fisk WJ. Health and productivity gains from better indoor environments and their relationship with building energy efficiency. Annu Rev Energy Environ 2000;25:537-66.

[50] Seppänen OA, Fisk W. Some quantitative relations between indoor environmental quality and work performance or health. HVAC R Res 2006;12:957-73. 
[51] Seppänen O, Fisk WJ. A conceptual model to estimate cost effectiveness of the indoor environment improvements. Proc. Heal. Build. 2003 Conf., vol. 3, Singapore: 2003, p. 368-74.

[52] Seppänen O, Fisk WJ, Lei QH. Room temperature and productivity in office work. Lawrence Berkeley Natl. Lab., vol. 1, Lisbon, Portugal: 2006, p. 1-5.

[53] Lan L, Wargocki P, Lian Z. Quantitative measurement of productivity loss due to thermal discomfort. Energy Build 2011;43:1057-62.

[54] Corsi RL. Connect or stagnate: The future of indoor air sciences. Indoor Air 2015;25:231-4.

[55] Kosonen R, Tan F. Assessment of productivity loss in air-conditioned buildings using PMV index. Energy Build 2004;36:987-93.

[56] Jensen KL, Toftum J, Friis-Hansen P. A Bayesian Network approach to the evaluation of building design and its consequences for employee performance and operational costs. Build Environ 2009;44:456-62.

[57] Lan L, Lian Z, Pan L, Ye Q. Neurobehavioral approach for evaluation of office workers' productivity: The effects of room temperature. Build Environ 2009;44:1578-88.

[58] Lan L, Lian Z, Pan L. The effects of air temperature on office workers' well-being, workload and productivityevaluated with subjective ratings. Appl Ergon 2010;42:29-36.

[59] Grether WF. Human performance at elevated environmental temperatures. Aerosp Med 1973;44:747-55.

[60] Ramsey JD, Morrissey SJ. Isodecrement curves for task performance in hot environments. Appl Ergon 1978;9:66-72.

[61] McIntyre DA. Indoor climate. London: Applied Science Publishers; 1980.

[62] Hancock PA. Task categorization and the limits of human performance in extreme heat. Aviat Space Environ Med 1982;53:778-84.

[63] Kobrick JL, Fine BJ. Climate and human performance. In: Oborne DJ, Gruneberg MM, editors. Phys. Environ. Work, Chichester, England: Wiley \& Sons; 1983, p. 69-107.

[64] Parsons K. Human Thermal Environments: The Effects of Hot, Moderate, and Cold Environments on Human Health, Comfort, and Performance. 3rd ed. London: Taylor \& Francis; 2014.

[65] Pilcher JJ, Nadler E, Busch C. Effects of hot and cold temperature exposure on performance: A meta-analytic review. Ergonomics 2002;45:682-98.

[66] Taylor L, Watkins SL, Marshall H, Dascombe BJ, Foster J. The Impact of Different Environmental Conditions on Cognitive Function: A Focused Review. Front Physiol 2016;6:372.

[67] Schmit C, Hausswirth C, Le Meur Y, Duffield R. Cognitive Functioning and Heat Strain: Performance Responses and Protective Strategies. Sport Med 2017;47:1289-302.

[68] López-Sánchez JI, Hancock PA. Thermal effects on cognition: a new quantitative synthesis. Int J Hyperth 2017;0:1-9.

[69] Sink D. Productivity Management: Planning, Measurement and Evaluation, Control and Improvement. New York: Wiley; 1985.

[70] Oseland NA. Environmental Factors Affecting Office Worker Performance: A Review of Evidence. London: CIBSE; 1999.

[71] Roelofsen P. The impact of office environments on employee performance: The design of the workplace as a strategy for productivity enhancement. J Facil Manag 2002;1:247-64.

[72] Clements-Croome, Derek E. Indoor environment and productivity. In: Clements-Croome, Derek E, editor. Creat. Product. Work. 2nd ed., London: Taylor \& Francis; 2006, p. 25-54.

[73] Onyeizu E. Can Architecture Increase Productivity? The Case of Green Certified Buildings. The University of Auckland, 2014.

[74] Fleishman EA, Ellison GD. A factor analysis of fine manipulation tests. J Appl Psychol 1962;46:96-105.

[75] Mawson A. The Workplace and its Impact on Productivity. London: 2002.

[76] Haynes BP. An evaluation of office productivity measurement. J Corp Real Estate 2007;9:144-55.

[77] Wiik R. Indoor productivity measured by common response patterns to physical and psychosocial stimuli. Indoor 
Air 2011;21:328-40.

[78] Clements-Croome, Derek E, Kaluarachchi Y. Assessment and measurement of productivity. In: ClementsCroome, Derek E, editor. Creat. Product. Work. 2nd ed., London: Taylor \& Francis; 2006, p. 129-66.

[79] Rasheed EO, Byrd H. Can self-evaluation measure the effect of IEQ on productivity? A review of literature. Facilities 2017.

[80] Leaman A, Bordass B. Productivity in buildings: the 'killer' variables. Build Res Inf 1999;27:4-19.

[81] Byrd H, Rasheed OE. The Productivity Paradox in Green Buildings. Sustainability 2016;8.

[82] Hedge A, Sakr W, Agarwal A. Thermal Effects on Office Productivity. Proc Hum Factors Ergon Soc Annu Meet 2005;49:823-7.

[83] Geng Y, Ji W, Lin B, Zhu Y. The impact of thermal environment on occupant IEQ perception and productivity. Build Environ 2017;121:158-67.

[84] Seppänen O, Fisk W, Faulkner D. Cost benefit analysis of the night-time ventilation cooling in office building. Proc. Heal. Build. 2003 Conf., Singapore: 2003, p. 394-9.

[85] Niemelä R, Hannula M, Rautio S, Reijula K, Railio J. The effect of air temperature on labour productivity in call centres - A case study. Energy Build 2002;34:759-64.

[86] Smither RD. The Psychology of Work and Human Performance. 3rd ed. New York: Addison-Wesley; 1998.

[87] Cairns G. Seeking a facilities management philosophy for the changing workplace. Facilities 2003;21:95-105.

[88] Gatersleben B, Griffin I. Environmental Stress. In: Fleury-Bahi G, Pol E, Navarro O, editors. Handb. Environ. Psychol. Qual. Life Res., Cham: Springer International Publishing; 2017, p. 469-85.

[89] Evans GW, Cohen SA. Environmental stress. In: Stokols D, Altman I, editors. Handb. Environ. Psychol., New York: Wiley; 1987.

[90] Duffy E. Activation and Behavior. New York: Wiley; 1962.

[91] Hebb DO. Drives and the C.N.S. (Conceptual Nervous System). Psychol Rev 1955;62:243-54.

[92] Lindsley DS. Emotion. In: Stevens SS, editor. Handb. Exp. Psychol., New York: Wiley; 1951, p. $473-516$.

[93] Hancock PA, Ganey HCN. From the Inverted-U to the Extended-U: The Evolution of a Law of Psychology. J Hum Perform Extrem Environ 2003;7.

[94] Corbett M. From law to folklore: work stress and the Yerkes-Dodson Law. J Manag Psychol 2015;30:741-52.

[95] Yerkes RM, Dodson JD. The relation of strength of stimulus to rapidity of habit- formation. J Comp Neurol Psychol 1908;18:459-82.

[96] Poulton EC, Kerslake DM. Initial stimulating effect of warmth upon perceptual efficiency. Aerosp Med 1965;36:29-32.

[97] Griffith ID, Boyce PR. Performance and Thermal Comfort. Ergonomics 1971;14:457-68.

[98] Poulton EC. Arousing Stresses Increase Vigilance. In: Mackie RR, editor. Vigil. Theory, Oper. Performance, Physiol. Correl. Mackie, R., Boston, MA: Springer US; 1977, p. 423-459.

[99] Wilkinson RT, Fox RH, Goldsmith R, Hampton IFG, Lewis HE. Psychological and physiological responses to raised body temperature. J Appl Physiol 1964;19:287-91.

[100] Jiang J, Wang D, Liu Y, Xu Y, Liu J. A study on pupils' learning performance and thermal comfort of primary schools in China. Build Environ 2018;134:102-13.

[101] Cui W, Cao G, Park JH, Ouyang Q, Zhu Y. Influence of indoor air temperature on human thermal comfort, motivation and performance. Build Environ 2013;68:114-22.

[102] Wyon DP, Fanger PO, Olesen BW, Pederson CJK. The Mental Performance of Subjects Clothed for Comfort at Two Different Air Temperatures. Ergonomics 1975;18:359-74.

[103] Wyon DP. Individual Microclimate Control: Required Range, Probable Benefits and Current Feasibility. Proc. 7th Int. Conf. Indoor Air Qual. Clim., vol. 1, Nagoya, Japan: 1996, p. 1067-72.

[104] Hancock PA, Warm JS. A Dynamic Model of Stress and Sustained Attention. Hum Factors J Hum Factors Ergon Soc 1989;31:519-37. 
[105] Kahneman D. Attention and Effort. Englewood Cliffs, NJ: Prentice Hall; 1973.

[106] Easterbrook JA. The effect of emotion on cue utilization and the organization of behavior. PG - 183-201. Psychol Rev 1959;66:183-201.

[107] Tanabe S, Nishihara N. Productivity and fatigue. Indoor Air, Suppl 2004;14:126-33.

[108] Witterseh T, Wyon DP, Clausen G. The effects of moderate heat stress and open-plan office noise distraction on SBS symptoms and on the performance of office work. Indoor Air 2004;14:30-40.

[109] Fang L, Wyon DP, Clausen G, Fanger PO. Impact of indoor air temperature and humidity in an office on perceived air quality, SBS symptoms and performance. Indoor Air, Suppl 2004;14:74-81.

[110] Haneda M, Wargocki P, Dalewski M, Tanabe SI. The effects of thermal discomfort on task performance, fatigue and mental work load examined in a subjective experiment. Proc. 9th Int. Conf. Exhib., Syracuse, New York: International Society of Indoor Air Quality and Climate ( ISIAQ ); 2009.

[111] Lan L, Lian Z. Use of neurobehavioral tests to evaluate the effects of indoor environment quality on productivity. Build Environ 2009;44:2208-17.

[112] Melikov AK, Skwarczynski MA, Kaczmarczyk J, Zabecky J. Use of personalized ventilation for improving health, comfort, and performance at high room temperature and humidity. Indoor Air 2013;23:250-63.

[113] Cui W, Cao G, Ouyang Q, Zhu Y. Influence of dynamic environment with different airflows on human performance. Build Environ 2013;62:124-32.

[114] Maula H, Hongisto V, Östman L, Haapakangas A, Koskela H, Hyönä J. The effect of slightly warm temperature on work performance and comfort in open-plan offices - a laboratory study. Indoor Air 2016;26:286-97.

[115] Zhang F, de Dear R. University students' cognitive performance under temperature cycles induced by direct load control events. Indoor Air 2017;27:78-93.

[116] Zhang F, Haddad S, Nakisa B, Rastgoo MN, Candido C, Tjondronegoro D, de Dear R. The effects of higher temperature setpoints during summer on office workers' cognitive load and thermal comfort. Build Environ 2017;123:176-88.

[117] Schiavon S, Yang B, Donner Y, Chang VWC, Nazaroff WW. Thermal comfort, perceived air quality, and cognitive performance when personally controlled air movement is used by tropically acclimatized persons. Indoor Air 2017;27:690-702.

[118] Liu W, Zhong W, Wargocki P. Performance, acute health symptoms and physiological responses during exposure to high air temperature and carbon dioxide concentration. Build Environ 2017;114:96-105.

[119] Hancock PA. Heat stress impairment of mental performance: a revision of tolerance limits. Aviat Space Environ Med 1981;52:177-80.

[120] Hancock PA. Sustained Attention Under Thermal Stress. Psychol Bull 1986;99:263-81.

[121] Carpenter A. The effect of room temperature of the Resistance Box Test: A performance test of intelligence. London: 1946.

[122] Pepler RD. Warmth and performance: An investigation in the tropics. Ergonomics 1958;2:63-88.

[123] Mackworth NH. Researches on the measurement of human performance. Oxford: His Majesty's Stationery Office; 1950.

[124] Fox RH, Gowsmith R, Hampton IFG, Wilkinson RT. The effects of a raised body temperature on the performance of mental tasks. J Physiol 1963;167:22-3.

[125] Bell CR, Provins KA, Hiorns RW. Visual and auditory vigilance during exposure to hot and humid conditions. Ergonomics 1964;7:279-88.

[126] Poulton EC. Environment and Human Efficiency. Springfield: Charles C. Thomas; 1970.

[127] Nunneley SA, Reader DC, Maldonado RJ. Head-temperature effects on physiology, comfort, and performance during hyperthermia. Aviat Space Environ Med 1982;53:623-8.

[128] Færevik H, Reinertsen RE. Effects of wearing aircrew protective clothing on physiological and cognitive responses under various ambient conditions. Ergonomics 2003;46:780-99.

[129] Simmons SE, Saxby BK, McGlone FP, Jones DA. The effect of passive heating and head cooling on perception, cardiovascular function and cognitive performance in the heat. Eur J Appl Physiol 2008;104:271-80. 
[130] Ramzjou S, Kjellberg A. Sustained attention and serial responding in heat: Mental effort in the control of performance. Aviat Sp Environ Med 1992;63:594-601.

[131] Banderet LE, MacDougall D, Roberts D, Tappan D, Jacey M. Effects of Hypohydration or Cold Exposure and Restricted Fluid Intake Upon Cognitive Performance. Natick, MA: DTIC Document; 1986.

[132] Sharma VM, Panwar MR. Variations in mental performance under moderate cold stress. Int J Biometeorol 1987;31:85-91.

[133] Palinkas LA, Mäkinen TM, Pääkkönen T, Rintamäki H, Leppäluoto J, Hassi J. Influence of seasonally adjusted exposure to cold and darkness on cognitive performance in circumpolar residents. Scand J Psychol 2005;46:23946.

[134] Thomas JR, Ahlers ST, House JF, Schrot J. Repeated exposure to moderate cold impairs matching-to-sample performance. Aviat Space Environ Med 1989;60:1063-7.

[135] Patil PG, Apfelbaum JL, Zacny JP. Effects of a cold-water stressor on psychomotor and cognitive functioning in humans. Physiol Behav 1995;58:1281-6.

[136] Mäkinen TM, Palinkas LA, Reeves DL, Pääkkönen T, Rintamäki H, Leppäluoto J, Hassi J. Effect of repeated exposures to cold on cognitive performance in humans. Physiol Behav 2006;87:166-76.

[137] Flouris AD, Westwood DA, Cheung SS. Thermal Balance Effects on Vigilance During 2-Hour Exposures To $-20^{\circ}$ C. Aviat Space Environ Med 2007;78:673-9.

[138] Teichner WH. Reaction time in the cold. J Appl Psychol 1958;42:54-9.

[139] Ellis HD. The effects of cold on the performance of serial choice reaction time and various discrete tasks. Hum Factors 1982;24:589-98.

[140] Watkins SL, Castle P, Mauger AR, Sculthorpe N, Fitch N, Aldous J, Brewer J, Midgley AW, Taylor L. The effect of different environmental conditions on the decision-making performance of soccer goal line officials. Res Sport Med 2014;22:425-37.

[141] Ely BR, Sollanek KJ, Cheuvront SN, Lieberman HR, Kenefick RW. Hypohydration and acute thermal stress affect mood state but not cognition or dynamic postural balance. Eur J Appl Physiol 2013;113:1027-34.

[142] Ramsey JD, Kwon YG. Recommended alert limits for perceptual motor loss in hot environments. Int J Ind Ergon 1992;9:245-57.

[143] Yeganeh AJ, Reichard G, McCoy AP, Bulbul T, Jazizadeh F. Correlation of ambient air temperature and cognitive performance: A systematic review and meta-analysis. Build Environ 2018.

[144] Wyon DP, Bruun NO, Olesen P, Kjerulf-Jensen P, Fanger PO. Factors affecting the subjective tolerance of ambient temperature swings. In: Salmark H, editor. Proc. 5th Int. Congr. Heating, Vent. Air Cond., Copenhagen: 1971, p. 87-107.

[145] Wyon DP, Asgeirsdottir T, Jensen PK, Fanger PO, Th. A, Jensen PK, Fanger PO. The effects of ambient temperature swings on comfort, performance and behavior. ArchSciPhysiol 1973;27:441-58.

[146] Newsham GR, Donnelly CL, Mancini S, Marchand RG, Lei W, Charles KE, Veitch JA. The effect of ramps in temperature and electric light level on office occupants: a literature review and a laboratory experiment. Proc. 2006 ACEEE Summer Study Energy Effic. Build., Pacific Grove, California: 2006, p. 252-64.

[147] Kolarik J, Toftum J, Olesen BW, Shitzer A. Occupant responses and office work performance in environments with moderately drifting operative temperatures (RP-1269). HVAC R Res 2009;15:931-60.

[148] Schellen L, van Marken Lichtenbelt WD, Loomans MGLC, Toftum J, de Wit MH. Differences between young adults and elderly in thermal comfort, productivity, and thermal physiology in response to a moderate temperature drift and a steady-state condition. Indoor Air 2010;20:273-83.

[149] McMorris T, Swain J, Smith M, Corbett J, Delves S, Sale C, Harris RC, Potter J. Heat stress, plasma concentrations of adrenaline, noradrenaline, 5-hydroxytryptamine and cortisol, mood state and cognitive performance. Int J Psychophysiol 2006;61:204-15.

[150] Amos D, Hansen R, Lau WM, Michalski JT. Physiological and cognitive performance of soldiers conducting routine patrol and reconnaissance operations in the tropics. Mil Med 2000;165:961-6.

[151] Cian C, Barraud PA, Melin B, Raphel C. Effects of fluid ingestion on cognitive function after heat stress or exercise-induced dehydration. Int J Psychophysiol 2001;42:243-51. 
[152] Sun G, Yang X, Jiang Q, Liu K, Li B, Li L, Zhao L, Li M. Hyperthermia impairs the executive function using the Attention Network Test. Int J Hyperth 2012;28:621-6.

[153] Liu K, Sun G, Li B, Jiang Q, Yang X, Li M, Li L, Qian S, Zhao L, Zhou Z, von Deneen KM, Liu Y. The impact of passive hyperthermia on human attention networks: An fMRI study. Behav Brain Res 2013;243:220-30.

[154] Ellis HD, Wilcock SE, Zaman SA. Cold and performance: the effects of information load, analgesics, and the rate of cooling. Aviat Space Environ Med 1985;56:233-237.

[155] Giesbrecht GG, Arnett JL, Vela E, Bristow GK. Effect of task complexity on mental performance during immersion hypothermia. Aviat Space Environ Med 1993;64:206-11.

[156] Kiyatkin EA. Brain hyperthermia as physiological and pathological phenomena. Brain Res Rev 2005;50:27-56.

[157] Qian S, Sun G, Jiang Q, Liu K, Li B, Li M, Yang X, Yang Z, Zhao L. Altered topological patterns of large-scale brain functional networks during passive hyperthermia. Brain Cogn 2013;83:121-31.

[158] Kiyatkin EA. Physiological and pathological brain hyperthermia. In: Sharma HS, editor. Prog. Brain Res., vol. 162, Elsevier; 2007, p. 219-43.

[159] Gopinathan PM, Pichan G, Sharma VM. Role of dehydration in heat stress-induced variations in mental performance. Arch Environ Health 1988;43:15-7.

[160] Bradley K, Higenbottam C. Cognitive performance: effect of drug-induced dehydration in RTO-MP-HFM-086Maintaining Hydration: Issues, Guidelines, and Delivery. Boston, MA: RTO Specialists Meeting; 2003.

[161] Choi H-H, van Merriënboer JJG, Paas F. Effects of the Physical Environment on Cognitive Load and Learning: Towards a New Model of Cognitive Load. Educ Psychol Rev 2014;26:225-44.

[162] Ayres P, Paas F. Cognitive load theory: New directions and challenges. Appl Cogn Psychol 2012;26:827-32.

[163] Paas F, Renkl A, Sweller J. Cognitive load theory and instructional design: Recent developments. Educ. Psychol., vol. 38, 2003, p. 1-4.

[164] Paas F, Renkl A, Sweller J. Cognitive Load Theory: Instructional Implications of the Interaction between Information Structures and Cognitive Architecture. Instr Sci 2004;32:1-8.

[165] Paas F, Sweller J. An Evolutionary Upgrade of Cognitive Load Theory: Using the Human Motor System and Collaboration to Support the Learning of Complex Cognitive Tasks. Educ Psychol Rev 2012;24:27-45.

[166] Paas FGWC, Van Merriënboer JJG. Instructional control of cognitive load in the training of complex cognitive tasks. Educ Psychol Rev 1994;6:351-71.

[167] Sweller J, van Merrienboer JJG, Paas FGWC. Cognitive Architecture and Instructional Design. Educ Psychol Rev 1998;10:251-96.

[168] Van Merriënboer JJG, Sweller J. Cognitive load theory and complex learning: Recent developments and future directions. vol. 17. 2005.

[169] Van Merriënboer JJG, Sweller J. Cognitive load theory in health professional education: Design principles and strategies. Med Educ 2010;44:85-93.

[170] Miller GA. the Magical Number 7, Plus or Minus 2 - Some Limits on Our Capacity for Processing Information. Psychol Rev 1956;63:81-97.

[171] Cowan N. The magical number 4 in short-term memory: A reconsideration of mental storage capacity. Behav Brain Sci 2001;24:87-114.

[172] Schacter Daniel L. The Seven Sins of Memory: How the Mind Forgets and Remembers. J Psychol Financ Mark 2001;2:1-184.

[173] Peterson L, Peterson MJ. Short-term retention of individual verbal items. J Exp Psychol 1959;58:193-8.

[174] Schneider W, Shiffrin RM. Controlled and automatic human information processing: I. Detection, search, and attention. Psychol Rev 1977;84:1-66.

[175] Shiffrin RM, Schneider W. Controlled and automatic human information processing: II. Perceptual learning, automatic attending and a general theory. Psychol Rev 1977;84:127-90.

[176] Nunneley SA, Dowd PJ, Myhre LG, Stribley RF, McNee RC. Tracking-Task Performance during Heat Stress Simulating Cockpit Conditions in High-Performance Aircraft. Ergonomics 1979;22:549-55. 
[177] Wyon DP, Andersen IB, Lundqvist GR. The effects of moderate heat stress on mental performance. Scand J Work Environ Health 1979;5:352-61.

[178] Drag LL, Bieliauskas LA. Contemporary review 2009: Cognitive aging. J Geriatr Psychiatry Neurol 2010;23:7593.

[179] Vercruyssen M. Slowing of behaviour with age. In: Kastenbaum R, editor. Encycl. adult Dev., Phoenix, AZ: Oryx Press; 1993, p. 457-467.

[180] Fozard JL, Vercruyssen M, Reynolds SL, Hancock PA, Quilter RE. Age Differences and Changes in Reaction Time: The Baltimore Longitudinal Study of Aging. J Gerontol 1994;49:P179-89.

[181] McDowd JM, Craik FI. Effects of aging and task difficulty on divided attention performance. J Exp Psychol 1988;14:267-80.

[182] Barr RA, Giambra LM. Age-related decrement in auditory selective attention. Psychol Aging 1990;5:597-9.

[183] Gunning-Dixon FM, Raz N. Neuroanatomical correlates of selected executive functions in middle-aged and older adults: a prospective MRI study. Neuropsychologia 2003;41:1929-41.

[184] Treitz FH, Heyder K, Daum I. Differential course of executive control changes during normal aging. Aging, Neuropsychol Cogn 2007;14:370-93.

[185] Gold D, Andres D, Arbuckle T, Schwartzman. Measurement and correlates of verbosity in elderly people. Journals Gerontol 1988;43.

[186] Rodriguez-Aranda C, Martinussen M. Age-Related Differences in Performance of Phonemic Verbal Fluency Measured by Controlled Oral Word Association Task (COWAT): A Meta-Analytic Study. Dev Neuropsychol 2006;30:697-717.

[187] Nilsson L-G. Memory function in normal aging. Acta Neurol Scand Suppl 2003;179:7-13.

[188] Spencer WD, Raz N. Differential Effects of Aging on Memory for Content and Context: A Meta-Analysis. Psychol Aging 1995;10:527-39.

[189] Henry JD, MacLeod MS, Phillips LH, Crawford JR. A Meta-Analytic Review of Prospective Memory and Aging. Psychol Aging 2004;19:27-39.

[190] Lawrence B, Myerson J, Hale S. Differential decline of verbal and visuospatial processing speed across the adult life span. Aging, Neuropsychol Cogn 1998;5:129-46.

[191] Jenkins L, Myerson J, Joerding JA, Hale S. Converging evidence that visuospatial cognition is more agesensitive than verbal cognition. Psychol Aging 2000;15:157-75.

[192] Trezza BM, Apolinario D, de Oliveira RS, Busse AL, Gonçalves FLT, Saldiva PHN, Jacob-Filho W. Environmental heat exposure and cognitive performance in older adults: a controlled trial. Age (Omaha) $2015 ; 37$.

[193] Wing JF. Upper Thermal Tolerance Limits for Unimpaired Mental Performance. Aerosp Med 1965;36:960-4.

[194] Fox RH, Goldsmith R, Hampton IF, Hunt TJ. Heat acclimatization by controlled hyperthermia in hot-dry and hot-wet climates. J Appl Physiol 1967;22:39-46.

[195] Garden JW, Wilson ID, Rasch PJ. Acclimatization of healthy young adult males to a hot-wet environment. J Appl Physiol 1966;21:665-9.

[196] Cheung SS, McLellan TM. Heat acclimation, aerobic fitness, and hydration effects on tolerance during uncompensable heat stress. J Appl Physiol 1998;84:1731-9.

[197] Patterson MJ, Taylor NAS, Amos D. Physical Work and Cognitive Function During Acute Heat Exposure Before and After Heat Acclimation (DSTO-TR-0683). Melbourne, Australia: Defence Science and Technology Organisation, Aeronautical and Maritime Research Laboratory; 1998.

[198] Radakovic SS, Maric J, Surbatovic M, Radjen S, Stefanova E, Stankovic N, Filipovic N. Effects of acclimation on cognitive performance in soldiers during exertional heat stress. Mil Med 2007;172:133-6.

[199] Epstein Y, Keren G, Moisseiev J, Gasko O, Yachin S. Psychomotor deterioration during exposure to heat. Aviat Space Environ Med 1980;51:607-10.

[200] Sharma VM, Sridharan K, Pichan G, Panwar MR. Influence of heat-stress induced dehydration on mental functions. Ergonomics 1986;29:791-9.

[201] Cian C, Koulmann N, Barraud PA, Raphel C, Jimenez C, Melin B. Influence of variations in body hydration on 
cognitive function: Effect of hyperhydration, heat stress, and exercise-induced dehydration. J Psychophysiol 2000;14:29-36.

[202] Lieberman HR, Bathalon GP, Falco CM, Kramer FM, Morgan CA, Niro P. Severe decrements in cognition function and mood induced by sleep loss, heat, dehydration, and undernutrition during simulated combat. Biol Psychiatry 2005;57:422-9.

[203] Neave N, Scholey AB, Emmett JR, Moss M, Kennedy DO, Wesnes KA. Water ingestion improves subjective alertness, but has no effect on cognitive performance in dehydrated healthy young volunteers. Appetite 2001;37:255-6.

[204] Szinnai G, Schachinger H, Arnaud MJ, Linder L, Keller U. Effect of water deprivation on cognitive-motor performance in healthy men and women. Am J Psychol 2005;289:R275-80.

[205] D’Anci KE, Mahoney CR, Vibhakar A, Kanter JH, Taylor HA. Voluntary Dehydration and Cognitive Performance in Trained College Athletes. Percept Mot Skills 2009;109:251-69.

[206] Kempton MJ, Ettinger U, Foster R, Williams SCR, Calvert GA, Hampshire A, Zelaya FO, O’Gorman RL, McMorris T, Owen AM, Smith MS. Dehydration affects brain structure and function in healthy adolescents. Hum Brain Mapp 2011;32:71-9.

[207] Gaoua N, Racinais S, Grantham J, El Massioui F. Alterations in cognitive performance during passive hyperthermia are task dependent. Int J Hyperth 2011;27:1-9.

[208] Gaoua N, Grantham J, Racinais S, El Massioui F. Sensory displeasure reduces complex cognitive performance in the heat. J Environ Psychol 2012;32:158-63.

[209] Allnutt MF, Allan JR. The effects of core temperature elevation and thermal sensation on performance. Ergonomics 1973;16:189-96.

[210] Cabanac M. Physiological Role of Pleasure. Science (80- ) 1971;173:1103-7.

[211] De Dear R. Revisiting an old hypothesis of human thermal perception: Alliesthesia. Build Res Inf 2011;39:10817.

[212] Parkinson T, De Dear R. Thermal pleasure in built environments: Physiology of alliesthesia. Build Res Inf 2015;43:288-301.

[213] De Dear RJ, Akimoto T, Arens EA, Brager G, Candido C, Cheong KWD, Li B, Nishihara N, Sekhar SC, Tanabe $\mathrm{S}$, Toftum J, Zhang H, Zhu Y. Progress in thermal comfort research over the last twenty years. Indoor Air 2013;23:442-61.

[214] Hoyt T, Arens E, Zhang H. Extending air temperature setpoints: Simulated energy savings and design considerations for new and retrofit buildings. Build Environ 2014.

[215] Zhang H, Arens E, Pasut W. Air temperature thresholds for indoor comfort and perceived air quality. Build Res Inf 2011;39:134-44.

[216] Zhang H, Arens E, Kim D, Buchberger E, Bauman F, Huizenga C. Comfort, perceived air quality, and work performance in a low-power task-ambient conditioning system. Build Environ 2010;45:29-39.

[217] Goldman RF. Productivity in the United States: A Question of Capacity or Motivation? ASHRAE Trans 1994;100:922-936.

[218] Hockey GR. Compensatory control in the regulation of human performance under stress and high workload; a cognitive-energetical framework. Biol Psychol 1997;45:73-93.

[219] Jahns DW. A concept of operator workload in manual vehicle operations. Meckenheim, Germany: Ges. zur Förderung d. Astrophysikal. Forschung; 1973.

[220] Johannsen G. Workload and Workload Measurement. Ment. Workload, 1979, p. 3-11.

[221] Keighren IM. Environmental Determinism. Int. Encycl. Soc. Behav. Sci., vol. 7. 2nd Editio, Oxford: Elsevier; 2015, p. 720-5.

[222] Hancock PA. Thermal comfort. In: Karwowski W, editor. Int. Encycl. Ergon. Hum. factors. 2nd ed., London: Taylor \& Francis; 2006, p. 1859-1862.

[223] Brager GS, De Dear RJ. Thermal adaptation in the built environment : a literature review. Energy Build 1998;27:83-96. 
[224] De Dear RJ, Brager GS. Developing an adaptive model of thermal comfort and preference. ASHRAE Trans 1998;104:1-18.

[225] Bäumler G. On the Validity of the Yerkes-Dodson Law. Stud Psychol (Bratisl) 1994;36:205-10.

[226] Bäumler G, Lienert G. Re-evaluation of the Yerkes-Dodson law by nonparametric tests of trend. Stud Psychol (Bratisl) 1993;35:431-6.

[227] Brown WP. The Yerkes-Dodson Law Repealed. Psychol Rep 1965;17:663-6.

[228] Pribram KH, McGuinness D. Arousal, activation, and effort in the control of attention. Psychol Rev 1975;82:116-49.

[229] Hockey GRJ, Hamilton P. The cognitive patterning of stress states. In: Hockey GRJ, editor. Stress fatigue Hum. Perform., New York: Wiley; 1983.

[230] Sanders AF. Towards a model of stress and human performance. Acta Psychol (Amst) 1983;53:61-97.

[231] Hockey GRJ, Galliard AWK, Coles MGH. Energetic aspects of human information processing. Dordrecht, the Netherlands: Martinus Nijhoff; 1986.

[232] Hancock PA. Stress and adaptability. In: Hockey GRJ, Galliard AWK, Coles MGH, editors. Energ. Asp. Hum. Inf. Process., Dordrecht, the Netherlands: Martinus Nijhoff; 1986, p. 243-251.

[233] Chong DSF, Van Eerde W, Rutte CG, Chai KH. Bringing employees closer: The effect of proximity on communication when teams function under time pressure. J Prod Innov Manag 2012;29:205-15.

[234] Stokes A, Kite K. Flight Stress: Stress, Fatigue and Performance in Aviation. Avebury Aviation; Brookfield, Vt., USA: Ashgate Pub. Co, Aldershot, Hants, England; 1994.

[235] Sonstroem R, Bernardo P. Intraindividual pregame state anxiety and basketball performance: A re-examination of the inverted-U curve. J Sport Psychol 1982;4:235-45.

[236] De Kloet ER, Oitzl MS, Joëls M. Stress and cognition: Are corticosteroids good or bad guys? Trends Neurosci 1999;22:422-6.

[237] Sweller J. Cognitive load during problem solving: Effects on learning. Cogn Sci 1988;12:257-85.

[238] Sweller J. Cognitive Load Theory, Learning Difficulty , and Instructional Design. Learn Instr 1994;4:295-312.

[239] Rohmert W. An International Symposium on Objective Assessment of Work Load in Air Traffic Control Tasks. Ergonomics 1971;14:545-7.

[240] Rohmert W. Psycho-physische Belastung und Beanspruchung von Fluglotsen. Berlin: Beuth-Vertrieb; 1973.

[241] Rolfe JM, Lindsay SJE. Flight deck environment and pilot workload: Biological measures of workload. Appl Ergon 1973;4:199-206.

[242] Moray N. Human Workload: Its Theory and Measurement. New York: Plenum Press; 1979.

[243] Hancock PA, Meshkati N. Human Mental Workload. Amsterdam: North-Holland; 1988.

[244] Meshkati N, Hancock PA, Rahimi M, Dawes SM. Techniques in mental workload assessment. In: Wilson JR, Corlett EN, editors. Eval. Hum. Work A Pract. Ergon. Methodol., Philadelphia, PA, US: Taylor \& Francis; 1995, p. 749-782.

[245] Hancock PA. Whither Workload? Mapping a Path for Its Future Development. In: Longo L, Leva MC, editors. Hum. Ment. Workload Model. Appl. First Int. Symp. H-WORKLOAD 2017, Cham: Springer International Publishing; 2017, p. 3-17.

[246] Fitts PM. The information capacity of the human motor system in controlling the amplitude of movement. J Exp Psychol 1954;47:381-91.

[247] Hancock PA, Newell KM. The movement speed-accuracy relationship in space-time. In: Heuer H, Kleinbeck U, Schmidt KH, editors. Mot. Behav. Program. Control Acquis., Berlin: Springer; 1985, p. 153-188.

[248] Lan L, Wargocki P, Lian Z. Thermal effects on human performance in office environment measured by integrating task speed and accuracy. Appl Ergon 2014;45:490-5.

[249] Wickelgren WA. Speed-accuracy tradeoff and information processing dynamics. Acta Psychol (Amst) 1977;41:67-85. doi:10.1016/0001-6918(77)90012-9.

[250] Hart SG, Staveland LE. Development of NASA-TLX (Task Load Index): Results of Empirical and Theoretical 
Research. In: Hancock PA, Meshkati N, editors. Adv. Psychol., North-Holland; 1988, p. 139-183.

[251] Reid GB, Nygren TE. The Subjective Workload Assessment Technique: A Scaling Procedure for Measuring Mental Workload. In: Hancock PA, Meshkati N, editors. Hum. Ment. Wokload, Amsterdam: Elsevier; 1988, p. $185-218$.

[252] Nayak T, Zhang T, Mao Z, Xu X, Zhang L, Pack DJ, Dong B, Huang Y. Prediction of Human Performance Using Electroencephalography under Different Indoor Room Temperatures. Brain Sci 2018;8:74.

[253] de Waard D. The measurement of drivers' mental workload. University of Groningen, Haren, The Netherlands, 1996.

[254] Brookhuis KA, de Waard D. Monitoring drivers' mental workload in driving simulators using physiological measures. Accid Anal Prev 2010;42:898-903.

[255] Sun G, Qian S, Jiang Q, Liu K, Li B, Li M, Zhao L, Zhou Z, von Deneen KM, Liu Y. Hyperthermia-Induced Disruption of Functional Connectivity in the Human Brain Network. PLoS One 2013;8:e61157.

[256] Pinti P, Aichelburg C, Lind F, Power S, Swingler E, Merla A, Hamilton A, Gilbert S, Burgess P, Tachtsidis I. Using Fiberless, Wearable fNIRS to Monitor Brain Activity in Real-world Cognitive Tasks. J Vis Exp 2015:e53336.

[257] Mulder G. The concept and measurement of mental effort. In: Hockey GRJ, Gaillard AWK, Coles MGH, editors. Energ. Hum. Inf. Process., Dordrecht, the Netherlands: Springer Netherlands; 1986, p. 175-98.

[258] Mulder LJM. Assessment of cardiovascular reactivity by means of spectral analysis. University of Groningen, The Netherlands, 1988.

[259] Mulder LJM. Measurement and analysis methods of heart rate and respiration for use in applied environments. Biol Psychol 1992;34:205-36.

[260] de Waard D, Brookhuis KA. Assessing driver status: A demonstration experiment on the road. Accid Anal Prev 1991;23:297-307.

[261] Mulder LJM. Estimating Mental Effort Using Heart Rate and Heart Rate Variability. In: Brookhuis KA, Stanton NA, Hedge A, Salas E, Hendrick HW, editors. Handb. Hum. Factors Ergon. Methods, CRC Press; 2004, p. 1-20.

[262] Teo G, Reinerman-Jones L, Matthews G, Szalma J, Jentsch F, Hudson I, Hancock PA. Selecting workload and stress measures for performance prediction. Proc Hum Factors Ergon Soc 2017;2017-Octob:2042-6.

[263] Zhao J, Zhu N, Lu S. Productivity model in hot and humid environment based on heat tolerance time analysis. Build Environ 2009;44:2202-7.

[264] Tawada T, Ikaga T, Murakami S, Uchida S, Ueda H. The total effect on performance and energy consumption caused by office's thermal environment. J Environ Eng (Transactions AIJ) 2010;75:213-9.

[265] Hox J. Multilevel Analysis : techniques and applications. 3rd ed. New York, NY: Routledge; 2017.

[266] Raudenbush SW, Bryk AS. Hierarchical linear models: Applications and data analysis methods. 2nd ed. Newbury Park, CA: SAGE Publications; 2002.

[267] Tabachnick BG, Fidell LS. Using multivariate statistics. 5th ed. Boston, MA: Pearson Education, Limited; 2013.

[268] Liang KY, Zeger SL. Regression Analysis for Correlated Data. Annu Rev Public Health 1993;14:43-68.

[269] Field A. Discovering Statistics using IBM SPSS Statistics. 4th Ed. SAGE Publications; 2013.

[270] Wargocki P, Wyon DP, Sundell J, Clausen G, Fanger PO. The Effects of Outdoor Air Supply Rate in an Office on Perceived Air Quality, Sick Building Syndrome (SBS) Symptoms and Productivity. Indoor Air 2000;10:22236.

[271] Wargocki P, Wyon DP. The Effects of Outdoor Air Supply Rate and Supply Air Filter Condition in Classrooms on the Performance of Schoolwork by Children. HVAC\&R Res 2007;13:165-91.

[272] Niemelä R, Railio J, Hannula M, Rautio S, Reijula K. Assessing the effect of indoor environment on productivity. Proc. Clima 2000 Conf., Napoli: 2001.

[273] Federspiel C, Liu G, Lahiff M, Faulkner D, Dibartolomeo D, Fisk W, Price P, Sullivan D. Worker Performance and Ventilation: Analysis of Individual Data for Call-Center Workers. Proc. Indoor Air 2002 Conf., 2002, p. 796-801.

[274] Tham KW. Effects of temperature and outdoor air supply rate on the performance of call center operators in the 
tropics. Indoor Air, Suppl 2004;14:119-25.

[275] Woods JE. Cost avoidance and productivity in owning and operating buildings. Occup Med (Chic Ill) 1989;4:753-70.

[276] Seppänen OA. Estimated cost of indoor climate in Finnish buildings. Proc. Indoor Air 1999, Edinburgh, Scotland: 1999, p. 13-8.

[277] Lan L, Wargocki P, Lian Z. Optimal thermal environment improves performance of office work. Indoor Environ 2012:12-7.

[278] Haldi F, Robinson D. Results from the monitoring of indoor environment and occupant perceived productivity in office buildings. Proc. Conf. Adapt. to Chang. New Think. Comf., Windsor, UK: 2010, p. 9-11.

[279] Link J, Pepler RD. Associated fluctuations in daily temperature, productivity and absenteeism. ASHRAE Trans 1970;76:326-37.

[280] Bank W. World Bank Open Data. World Bank Open Data 2018. https://data.worldbank.org (accessed November 19, 2018).

[281] Jin Q, Duanmu L, Zhang H, Li X, Xu H. Thermal sensations of the whole body and head under local cooling and heating conditions during step-changes between workstation and ambient environment. Build Environ 2011;46:2342-50.

[282] Zhai Y, Zhang H, Zhang Y, Pasut W, Arens E, Meng Q. Comfort under personally controlled air movement in warm and humid environments. Build Environ 2013;65:109-17.

[283] Ghahramani A, Zhang K, Dutta K, Yang Z, Becerik-Gerber B. Energy savings from temperature setpoints and deadband: Quantifying the influence of building and system properties on savings. Appl Energy 2016;165:930 42. 